\title{
Continuous Doppler sounding of the ionosphere during solar flares
}

\author{
Jaroslav Chum ${ }^{1 *} \mathbb{D}$, Jaroslav Urbár ${ }^{1}$, Jan Laštovička' ${ }^{1}$ Miguel Angel Cabrera², Jann-Yenq Liư ${ }^{3}$, \\ Fernando Alberto Miranda Bonomi ${ }^{2}$, Mariano Fagre ${ }^{2,4}$, Jiří Fišer ${ }^{1}$ and Zbyšek Mošna ${ }^{1}$
}

\begin{abstract}
Solar flares cause a rapid increase in ionization in the ionosphere owing to significant enhancement of ionizing solar radiation in the X-ray and extreme ultraviolet (EUV) spectral ranges. The change of electron densities in the ionosphere influences the propagation of radio waves. The ionospheric response to solar flares is investigated for three selected examples recorded during the maximum and decreasing phase of the solar cycle 24 with time resolution of several seconds by continuous Doppler sounding systems installed in the Czech Republic (50N, 14E), Taiwan (24N, $121 \mathrm{E}$ ) and Northern Argentina $(27 \mathrm{~S}, 65 \mathrm{~W})$. The reflection heights of sounding signals are derived from nearby ionospheric sounders. The measured Doppler shifts are compared with EUV and X-ray data from the GOES-15 satellite. It is shown that the largest Doppler shifts are observed at times when the time derivatives of EUV fluxes are maximal, while the Doppler shifts are around zero at times when the EUV fluxes reach maxima. This means that loss processes balance the ionization when the EUV fluxes maximize. The attenuation of Doppler signal caused by enhanced electron density in the $\mathrm{D}$ and $\mathrm{E}$ layer was well correlated with the cosmic noise absorption measured by riometer. For large ionizing fluxes, the attenuation leads to very low signal-to-noise ratio, loss of the received signal, and inability to process both Doppler shift spectrograms and ionograms.
\end{abstract}

Keywords: Ionosphere, Solar flares, HF Doppler sounding, Radio waves

\section{Introduction}

The electromagnetic radiation from the Sun covers a broad range of frequency spectra from radio waves to $\mathrm{X}$-rays, the largest power spectral density being in the visible range of spectrum. The total solar irradiance at the Earth's orbit is around $1366 \mathrm{~W} \mathrm{~m}^{-2}$ and its variability through a solar cycle usually does not exceed $0.1 \%$ (Fröhlich 2009; Kopp 2016). Fluctuations in the EUV and X-ray part of the solar flux are much larger. The radiated X-ray flux can increase by several orders of magnitude during solar flares. The changes of EUV and X-ray radiation are one of the main causes of ionospheric variability as the EUV and X-ray fluxes are responsible for the photoionization of the upper atmosphere and formation of the ionosphere. Photoionization takes place if the energy of

\footnotetext{
*Correspondence: jachu@ufa.cas.cz

${ }^{1}$ Institute of Atmospheric Physics CAS, Bocni II/1401, 14131 Prague 4, Czech Republic

Full list of author information is available at the end of the article
}

ionizing photons exceeds the ionization threshold energies of atoms and molecules in the upper atmosphere. The ionization thresholds-maximum wavelengths of photons that ionize the most important species in the thermosphere/ionosphere of $\mathrm{O}_{2}, \mathrm{NO}, \mathrm{O}, \mathrm{He}$ and $\mathrm{H}$ are $102.8,133.8,91.03,50.42$, and $91.16 \mathrm{~nm}$, respectively (Shunk and Nagy 2009). The molecular ions $\mathrm{O}_{2}{ }^{+}$and $\mathrm{NO}^{+}$prevail in the lower ionosphere (D and $\mathrm{E}$ region), the atomic ion $\mathrm{O}^{+}$is dominant in the F2 layer, including the peak of the ionosphere. At altitudes higher than $600-1000 \mathrm{~km}$, the $\mathrm{H}^{+}$ions (protons) are the most common ion species.

In this paper, sudden ionospheric disturbances (SIDs) owing to rapid enhancement of solar EUV and X-ray fluxes during solar flares are investigated. The paper is based on experimental measurements of EUV and $\mathrm{X}$-ray flux by satellites and on monitoring of SIDs by continuous Doppler sounding, together with measurements by ionosondes and riometer. It partly builds on previous works, mainly on those by Mitra (1974) and 
Liu et al. (1996). Contrary to previous studies, the data are presented with much better time resolution (several seconds) and sudden frequency deviations observed by continuous Doppler sounding are investigated together with signal absorption. The signal absorption occurs as a consequence of collisions between neutral particles and electrons owing to enhanced electron density in the lower ionosphere, especially in the D layer. The flareenhanced ionization in the $\mathrm{D}$ layer can also be observed as cosmic noise absorption at frequencies of several tens of $\mathrm{MHz}$ measured by riometers, as amplitude and phase changes of signals from VLF transmitters propagating in the Earth-ionosphere waveguide or as sudden wave fadeouts (SWFs) at frequencies of units of $\mathrm{MHz}$ (Laštovička 2009; Silber and Price 2016). Atmospherics (low frequency electromagnetic signals generated by lightning) have also been used to probe the response of D layer to solar flares (Han and Cummer 2010). Han and Cummer (2010) found that the reflection height of atmospherics decreased by about $6 \mathrm{~km}$ if the X-ray flux measured in the spectral range $0.1-0.8 \mathrm{~nm}$ increased ten times. Their results are in agreement with previous studies based on narrow band measurements of signals from VLF transmitters (McRae and Thomson 2004). We will use this estimate of the decrease in electron density profile in $\mathrm{D}$ layer in our study. Solar flares can also cause decrease in echo power or short-wave fadeouts of SuperDARN HF radar signals (Watanabe and Nishitani 2013; Chakraborty et al. 2018; Fiori et al. 2018). The paper is organized as follows: Second section describes measurements and discusses data analysis. Third section analyzes the observations in the Czech Republic, Taiwan and Argentina. Fourth section discusses the obtained results. The last section provides a brief summary.

\section{Measurements and data analysis \\ Continuous Doppler sounding}

Continuous Doppler sounding is a relatively simple method to investigate dynamics of the ionosphere on short time scales with a time resolution of several seconds. It is based on the transmission of a stable sine wave at a frequency of several $\mathrm{MHz}$ that reflects from the ionosphere, roughly at the height where its frequency $f$ matches the local plasma frequency, $f_{\mathrm{p}}$. The reflection is exactly at $f=f_{\mathrm{p}}$ for vertically propagating ordinary wave. Reflection of oblique and extraordinary waves, with application to continuous Doppler sounding, was recently discussed by Chum et al. (2016). If the reflection region moves up and down or if there are plasma density changes along the sounding radio wave, the received signal experiences Doppler shift $f_{\mathrm{D}}$ that can be expressed as the time derivative of the phase path of the radio signal (Davies et al. 1962; Jacobs and Watanabe 1966),

$$
f_{\mathrm{D}}=-2 \cdot \frac{f}{c} \frac{\mathrm{d}}{\mathrm{d} t}\left(\int_{0}^{z_{R}} n \cdot \mathrm{d} r\right)=-2 \cdot \frac{f}{c} \int_{0}^{z_{R}} \frac{\partial n}{\partial N} \cdot \frac{\partial N}{\partial t} \cdot \mathrm{d} r
$$

where $c$ is the speed of light, $n$ is the real part of refractive index for electromagnetic waves, $N$ is the electron (plasma) density, and $z_{R}$ is the height of reflection. The $\partial n / \partial N$ term is usually important only close to the reflection region. The time derivative $\partial N / \partial t$ in Eq. (1) can be decomposed using the equation of continuity as:

$$
\frac{\partial N}{\partial t}=-\nabla N \cdot u_{P}-N\left(\nabla \cdot u_{\mathrm{P}}\right)+p-l,
$$

where $u_{\mathrm{P}}$ is the radial velocity of plasma motion, $p$ is electron production (owing to photoionization), and $l$ represents losses of free electrons (Liu et al. 1996).

The first term on the right-hand side of Eq. (2) corresponds to the advection, i.e., to radial motion of the reflection region (usually the vertical motion is the most important). The advection term dominates whether the plasma motion is caused by atmospheric gravity waves (GWs) or $\boldsymbol{E x} \boldsymbol{B}$ drift, associated with, e.g., magnetohydrodynamic waves (Sutcliffe and Poole 1989). The second term represents the plasma compression and rarefaction (mainly in the reflection region), and it is important in the analysis of infrasound waves (Chum et al. 2016). The increase in photoionization during distinct solar flares can cause sudden frequency deviations (SFDs). The observed Doppler shift is then mainly given by the difference (imbalance) between the rapid electron production and losses, $p-l$, and the contributions of the advection and compression terms to the observed Doppler shift can be usually neglected.

It is useful to investigate the simplest case when the first term (advection) dominates over the compression and $p-l$ terms. Then, the approximation of mirrorlike reflection can be applied, and the radial velocity $u_{\mathrm{P}}$ of plasma movement (vertical velocity, if the horizontal gradients can be neglected) can be calculated from the observed Doppler shift $f_{\mathrm{D}}$ as

$$
u_{\mathrm{p}}=-\frac{c}{2 f} f_{\mathrm{D}},
$$

The change of reflection height $\Delta h$ can be calculated by Eq. (4) provided that the refractive index (electron density) below the reflection region does not change significantly.

$$
\Delta h(t)=z_{R}(t)-z_{R}\left(t_{0}\right)=\int_{t_{0}}^{t} u_{\mathrm{p}} \mathrm{d} \tau=-\frac{c}{2 f} \int_{t_{0}}^{t} f_{\mathrm{D}} \mathrm{d} \tau,
$$


If the imbalance $p-l$ is much larger than the advection and compression $(\partial N / \partial t \approx p-1)$, then it is useful to introduce a virtual velocity $\mathrm{u}_{\mathrm{p}}^{*}$ which is related to the observed Doppler shift by Eq. (3). This is similar to the approach used by previous authors (Sutcliffe and Poole 1989; Liu and Berkey 1994 and references therein) to investigate the relative role of compression and advection mechanisms on the observed Doppler shift. The virtual velocity $u_{p}^{*}$ shall not be confused with the real velocity of radial motion $u_{p}$. The $u_{p}^{\prime \prime}$ is just an apparent velocity that we obtain from the observed Doppler shift $f_{D}$ applying Eq. (3), regardless of the mechanism that causes the Doppler shift; note that the Doppler shift is related with the rate of electron density changes, $\partial \mathrm{N} / \partial \mathrm{t}$, by Eq. (1). Using the equation of continuity (2), Eq. (3) for $u_{p}^{*}$ and assuming only vertical plasma gradients for simplicity, we get Eq. (5) that relates the $\mathrm{p}-\mathrm{l}$ term and the observed Doppler shift $f_{D}$, under the assumption that the Doppler shift $\left(\mathrm{u}_{\mathrm{p}}^{*}\right)$ arises only from $\mathrm{p}-\mathrm{l}$ imbalance $\left(\mathrm{u}_{\mathrm{P}} \approx 0\right)$.

$$
\frac{\partial N}{\partial t}=P-L=-\frac{\partial N}{\partial z} u_{\mathrm{p}}^{*}=\frac{c}{2 f} \frac{\partial N}{\partial z} f_{\mathrm{D}},
$$

where the gradient $\partial \mathrm{N} / \partial \mathrm{z}$ can be calculated from the electron densities obtained by an ionospheric sounder for the height of reflection. Thus, the implementation of the virtual velocity makes it possible to determine the rate of temporal electron density changes from the observed Doppler shift. It should be noted that the rate of electron density change in the reflection region, $\partial \mathrm{N} / \partial \mathrm{t}$, can only be related to the observed Doppler shift $f_{D}$ by Eq. (5) if the change of refractive index $\mathrm{n}$ below the reflection region is negligible. Otherwise, $f_{D}$ has to be calculated by integral in Eq. (1), which is obviously difficult in the experiment. It follows from the dispersion relation that substantial changes of $n$ with increasing/decreasing electron densities $\mathrm{N}, \partial \mathrm{n} / \partial \mathrm{N}$, only occur if the sounding frequency approaches the local plasma frequency. Thus, Eq. (5) is a good approximation if there are no electron density peaks-plasma frequency peaks below the reflection region that approach the values of sounding frequency. A similar problem can also arise if the sounding radio wave reflects near the peak of F2 layer as it then propagates relatively long trajectory through a region in which $\mathrm{n}$ approaches zero and is extremely sensitive to electron density changes. The steeper the gradient $\partial \mathrm{N} / \partial \mathrm{z}$, the more accurate are the approximations specified by Eqs. (3) and (5). If Eq. (5) can be applied, then the local electron density change $\Delta \mathrm{N}$ in the reflection region during the solar flare can be calculated as:

$$
\Delta N(t)=N(t)-N\left(t_{0}\right)=\frac{c}{2 f} \int_{t_{0}}^{t} \frac{\partial N}{\partial z} f_{\mathrm{D}} \mathrm{d} \tau,
$$

If $\partial \mathrm{N} / \partial \mathrm{z}$ does not change with time significantly, then Eq. (6) can be simplified to

$$
\Delta N(t)=N(t)-N\left(t_{0}\right)=\frac{c}{2 f} \frac{\partial N}{\partial z} \int_{t_{0}}^{t} f_{\mathrm{D}} \mathrm{d} \tau,
$$

It should be noted that if the gradient $\partial \mathrm{N} / \partial \mathrm{z}$ is approximately constant around the reflection region (with respect to $\Delta \mathrm{h}$ ), then Eqs. (4) and (7) give an equivalent shift of electron density profile at the height of reflection as $\Delta \mathrm{N}=-\partial \mathrm{N} / \partial \mathrm{z} \cdot \Delta \mathrm{h}$. In other words, for the approximately constant $\partial \mathrm{N} / \partial \mathrm{z}$ around the reflection region, it does not matter which mechanism (advection or $\mathrm{p}-1$ imbalance) dominates as the shift of the electron density profile calculated from the observed Doppler shift $f_{D}$ is the same. As discussed before, the derivation of this statement is based on the assumption that there are no regions with similar values of plasma frequency below the reflection region.

Examples of distinct SIDs observed by multi-point continuous Doppler sounding systems (CDSS) located in the Czech Republic $\left(\sim 50.3^{\circ} \mathrm{N}, 14.5^{\circ} \mathrm{E}\right)$, Taiwan $\left(\sim 23.9^{\circ} \mathrm{N}\right.$, $\left.121.2^{\circ} \mathrm{E}\right)$ and northern Argentina $\left(\sim 26.8^{\circ} \mathrm{S}, 65.2^{\circ} \mathrm{W}\right)$ will be presented. These systems were originally installed to observe propagation of GWs. So, each system is composed of at least three transmitters and one receiver as the time delays between the corresponding signatures observed on different sounding paths (transmitter-receiver pairs) can be used to calculate propagation velocities of GWs; more details about the GW measurement can be found in Chum et al. (2014). The distances between transmitters and receivers are usually in the range from 50 to $120 \mathrm{~km}$; an exception is the transmitter Tx2 in the Czech Republic which is at about $7 \mathrm{~km}$ distance from the receiver located in Prague. The coordinates of the individual transmitters and receivers are listed in Table 1 . In addition, Fig. 1 presents the locations of transmitters and receiver in the latitudelongitude plot for the Czech Republic. The frequencies of individual transmitters in each country are mutually offset by about $4 \mathrm{~Hz}$ to avoid their frequency overlap and to display the received signals in one Doppler shift spectrogram using one spectral analysis. Thus, the signals displayed in original Doppler shift spectrograms have different offsets. To distinguish it from the real Doppler shift, the y-axis in Doppler shift spectrogram is labeled $\Delta \mathrm{f}$, whereas the variables corresponding to the real Doppler shift (with removed offset) will be named $f_{D}$. The transmitted power is only $1 \mathrm{~W}$. In the case of SFDs induced by solar flares, the SFDs are observed at the same time on all the sounding paths. Also, the SFDs are practically the same in all the sounding paths (for the same operating frequency) with respect to horizontal distances between the different reflection points 
Table 1 Coordinates of transmitters ( $T \mathbf{x})$ and receivers ( $R \mathbf{x})$

\begin{tabular}{lccl}
\hline Country/device & Latitude $\left(^{\circ}\right.$ ) & Longitude $\left(^{\circ}\right)$ & Frequency $(\mathbf{M H z})$ \\
\hline Czech Republic/Rx & 50.041 & 14.477 & $3.59 / 4.65 / 7.04$ \\
Czech Republic/Tx1 & 50.528 & 14.567 & $3.59 / 4.65 / 7.04$ \\
Czech Republic/Tx2 & 49.991 & 14.538 & $3.59 / 4.65 / 7.04$ \\
Czech Republic/Tx3 & 50.648 & 13.656 & $3.59 / 4.65 / 7.04$ \\
Taiwan/Rx0 & 24.972 & 121.192 & 6.57 \\
Taiwan/Rx1 & 23.955 & 120.927 & 6.57 \\
Taiwan/Tx1 & 23.897 & 121.551 & 6.57 \\
Taiwan/Tx2 & 24.341 & 120.778 & 6.57 \\
Taiwan/Tx3 & 24.816 & 121.727 & 6.57 \\
Argentina/Rx & -26.84 & -65.23 & 4.63 \\
Argentina/Tx1 & -26.943 & -65.707 & 4.63 \\
Argentina/Tx2 & -26.563 & -64.550 & 4.63 \\
Argentina/Tx3 & -27.499 & -64.874 & 4.63 \\
\hline
\end{tabular}

(tens of $\mathrm{km}$ ); horizontal gradients of background plasma can be neglected. The operating frequency is $6.57 \mathrm{MHz}$ in Taiwan and $4.63 \mathrm{MHz}$ in Argentina. There are three multi-point CDSSs in the Czech Republic working at frequencies of $3.59,4.65$ and $7.04 \mathrm{MHz}$; the transmitters corresponding to different sounding frequencies are collocated (Table 1). Thus, SFDs can be observed at three different heights above the same place, provided that the critical frequency of the ionosphere foF2 is larger than the sounding frequency $f$. More precisely, it is enough if the critical frequency for the extraordinary wave is larger, $f x F 2>f$, to get a reflection from the ionosphere. The reflection heights can be estimated from ionograms measured by nearby ionospheric sounders. The nearby ionospheric sounders worked with sampling periods of 15,10 , and $5 \mathrm{~min}$ in the Czech Republic, Argentina and Taiwan, respectively. The ionospheric sounders in the Czech Republic and Argentina are located within $7 \mathrm{~km}$ from the receivers of the CDSSs; the ionosonde in Taiwan is at about $50 \mathrm{~km}$ distance. In all locations, the ionosondes sound almost the same column of ionospheric plasma as the corresponding CDSSs since the horizontal distances between reflection points of CDSSs and ionosondes are within few tens of kilometers. The new ionospheric sounder DPS 4 located in the Czech Republic makes it also possible to measure Doppler shifts (drift measurement). Its sampling period of $15 \mathrm{~min}$ (5 min in special campaigns) is, however, too low to study fast fluctuations as SFD, infrasound or short-period GWs. Such

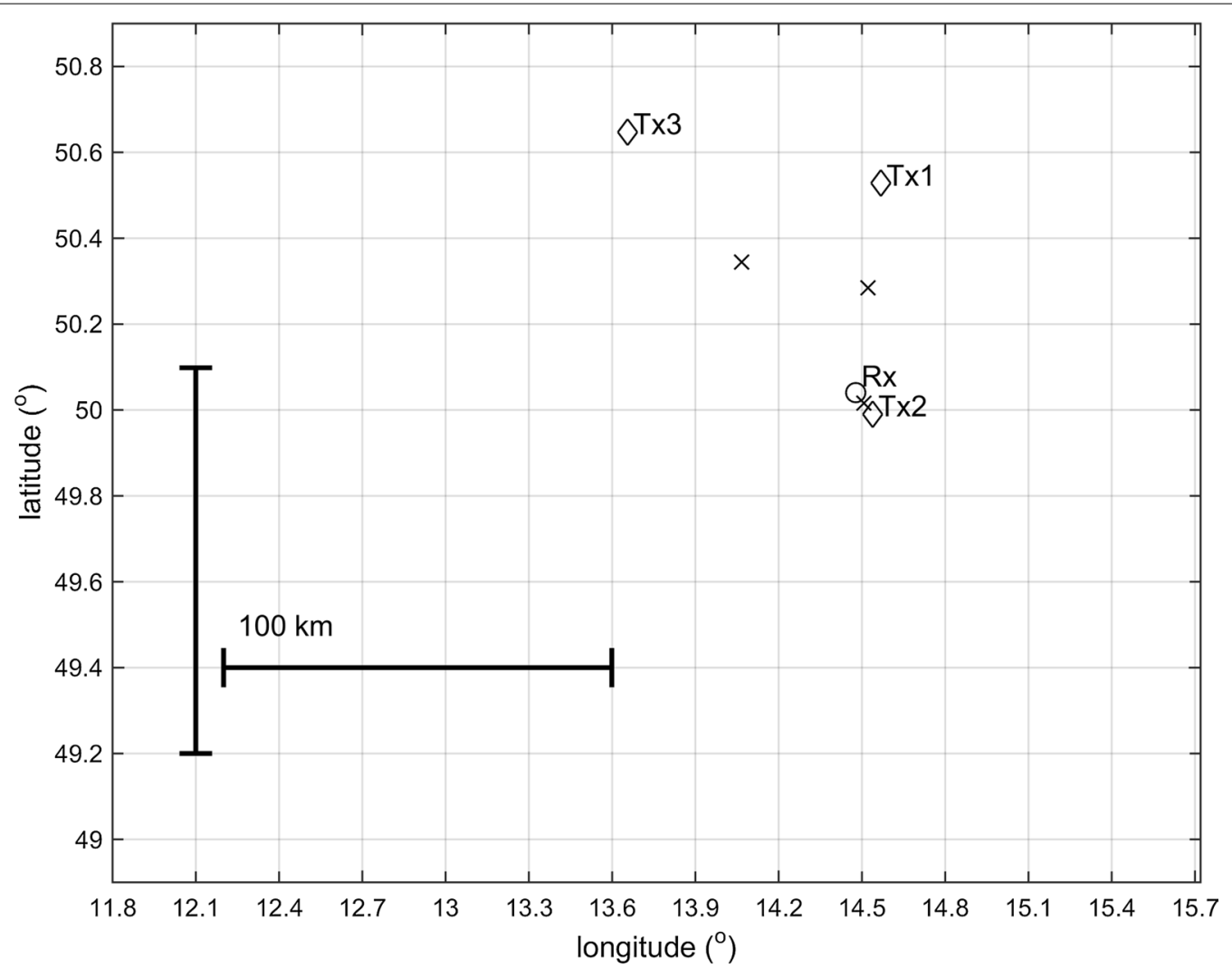

Fig. 1 Geographical locations of transmitters (diamonds), receiver (circle) and assumed reflection points (crosses) of the CDSS installed in the Czech Republic 
investigations are possible by using CDSS. The time resolution of the CDSS depends on the time intervals over which the spectral analysis (FFT with overlapping time windows) is performed. The better the time resolution, the worse the frequency resolution, and vice versa. The time resolution of $6 \mathrm{~s}$ is used in this study. The primary data processing is described in more detail by Chum et al. (2018).

\section{Attenuation of radio signal in the ionosphere}

Attenuation A of wave amplitude for wave propagating from $\mathrm{Z} 0$ to $\mathrm{Z}$ can be estimated from the imaginary part of wave vector $\operatorname{Im}(k)$ as:

$$
A=e^{-\int_{Z 0}^{Z} \operatorname{Im}(k) \mathrm{d} z} .
$$

In experiment, it is often convenient to express the attenuation in $\mathrm{dB}$. Considering that the attenuation below the ionosphere (below Z0) can be neglected and that the upward propagating wave and the downward propagating wave (after reflection from the ionosphere at Z) experience the same ionospheric conditions, the attenuation in $\mathrm{dB}$ related to the lossless case can be calculated by Eq. (9)

$$
A_{\mathrm{dB}}=20 \cdot \log _{10}\left(e^{-2 \int_{Z 0}^{Z} \operatorname{Im}(k) \mathrm{d} z}\right) .
$$

Attenuation of radio signal in the ionosphere is caused by collisions between neutral particles and electrons oscillating in the wave electric field, which mainly occurs in the lower ionosphere. The complex wave vector for radio waves, and hence also its imaginary part $\operatorname{Im}(\mathrm{k})$, can be obtained if the mass of electron $\mathrm{m}_{\mathrm{e}}$ is substituted by $\mathrm{m}_{\mathrm{e}}(1+\mathrm{i} v / \omega)$ in the collisionless dispersion relation (e.g., Gurnett and Bhatacharjee 2005), where $v$ is the collision frequency, $\mathrm{i}^{2}=-1$, and $\omega$ is the angular frequency of radio wave $(\omega=2 \pi f)$. The general dispersion relation with complex wave vector, and the expression for the imaginary part $\operatorname{Im}(\mathrm{k})$ is algebraically rather complicated. So, it is first useful to apply simplifying assumptions to have an idea about $\operatorname{Im}(\mathrm{k})$ value and its dependence on $v, \omega$, and plasma frequency $\omega_{\mathrm{p}}$. Assuming zero magnetic field $(\boldsymbol{B}=0)$, the dispersion relation for electromagnetic waves in cold plasma is given by Eq. (10), e.g., Gurnett and Bhatacharjee (2005).

$$
n=\frac{k c}{\omega}=\sqrt{1-\frac{\omega_{\mathrm{p}}^{2}}{\omega^{2}}}
$$

where the square of angular plasma frequency $\omega_{\mathrm{p}}^{2}$ is directly proportional to electron density $\mathrm{N}$ and is defined as follows: $\omega_{\mathrm{p}}^{2}=\mathrm{Ne}^{2} /\left(\mathrm{m}_{\mathrm{e}} \varepsilon_{0}\right)$, where e is the charge of an electron and $\varepsilon_{0}$ is the permittivity of vacuum. Substituting now the electron mass $m_{e}$ by $m_{e}(1+i v / \omega)$ in the relation for $\omega_{\mathrm{p}}^{2}$ and rearranging (10) to express the wave vector $k$, we get

$$
\begin{aligned}
k & =\frac{\omega}{c} \sqrt{1-\frac{\omega_{\mathrm{p}}^{2}}{\omega^{2}\left(1+i \frac{v}{\omega}\right)}} \approx \frac{\omega}{c}\left(1-\frac{1}{2} \frac{\omega_{\mathrm{p}}^{2}}{\omega^{2}\left(1+i \frac{v}{\omega}\right)}\right) \\
& =\frac{\omega}{c}\left(1-\frac{1}{2} \frac{\omega_{\mathrm{p}}^{2}}{\omega^{2}\left(1+\frac{\nu^{2}}{\omega^{2}}\right)}\right)+i \frac{1}{2 c} \frac{\omega_{\mathrm{p}}^{2} v}{\omega^{2}\left(1+\frac{\nu^{2}}{\omega^{2}}\right)}
\end{aligned}
$$

The terms after approximation (marked by $\approx$ ) are correct only for $\omega^{2} \gg \omega_{\mathrm{p}}^{2}$. If $v^{2} \ll \omega^{2}$ in addition, then the imaginary part $\operatorname{Im}(\mathrm{k})$ can be further simplified:

$$
\operatorname{Im}(k)=\frac{1}{2 c} \frac{\omega_{\mathrm{p}}^{2} \nu}{\omega^{2}\left(1+\frac{v^{2}}{\omega^{2}}\right)} \approx \frac{1}{2} \frac{\omega_{\mathrm{p}}^{2}}{\omega^{2}} \frac{\nu}{c} .
$$

This means that for $\omega_{\mathrm{p}}^{2} \ll \omega^{2}$ and $v^{2} \ll \omega^{2}$, the attenuation is proportional to the square of the inverse radio frequency, $1 / \omega^{2}$. The inequality $\omega_{\mathrm{p}}^{2} \ll \omega^{2}$ is satisfied in the D layer, where collisions are dominant for frequencies larger than about $1 \mathrm{MHz}$. On the other hand, the inequality $v^{2} \ll \omega^{2}$ might not be satisfied in the D layer.

Magnetized plasma supports two propagating modes. Following Stix (1962) and Gurnett and Bhatacharjee (2005), the full dispersion relation for the cold magnetized plasma can be written in the form:

$$
A n^{4}-B n^{2}+R L P=0
$$

where $\mathrm{A}=\mathrm{S} \cdot \sin ^{2} \Theta+\mathrm{P} \cdot \cos ^{2} \Theta, \mathrm{B}=\mathrm{R} \cdot \mathrm{L} \cdot \sin ^{2} \Theta+\mathrm{P} \cdot \mathrm{S} \cdot\left(1+\cos ^{2} \Theta\right)$, $\mathrm{R}=1-\omega_{\mathrm{p}}^{2} /\left[\omega\left(\omega+\omega_{\text {ce }}\right)\right], \mathrm{L}=1-\omega_{\mathrm{p}}^{2} /\left[\omega\left(\omega-\omega_{\mathrm{ce}}\right)\right], \mathrm{S}=0.5 \cdot(\mathrm{R}+\mathrm{L})$, $\mathrm{D}=0.5 \cdot(\mathrm{R}-\mathrm{L}), \mathrm{P}=1-\omega_{\mathrm{p}}^{2} / \omega^{2}, \omega_{\mathrm{ce}}=-\mathrm{eB} / \mathrm{m}_{\mathrm{e}}$ and $\Theta$ is the angle between magnetic field vector $\boldsymbol{B}$ and wave vector. Only electron terms are considered for simplicity as we are interested in the propagation at frequencies larger than $\omega_{\mathrm{p}}$. Equation (13) is a quadratic equation for the square of refractive index, $\mathrm{n}^{2}$. Two different solutions of (13) for $\mathrm{n}^{2}$ correspond to ordinary L-O and extraordinary $\mathrm{R}$-X modes. The refractive index now also depends on the strength of magnetic field (via the electron cyclotron frequency $\omega_{\text {ce }}$ ) and on the angle $\Theta$. The effect of collisions and attenuation can again be studied by substituting the $\mathrm{m}_{\mathrm{e}}$ by $\mathrm{m}_{\mathrm{e}}(1+\mathrm{i} v / \omega)$ in the relations for $\omega_{\mathrm{p}}^{2}$ and $\omega_{\mathrm{ce}}$. The algebraic expression for the $\operatorname{Im}(k)$ for the ordinary L-O and extraordinary R-X modes is extremely complicated. Fortunately, modern programming languages and computers make calculations with specific complex numbers possible. The calculated values of $\operatorname{Im}(\mathrm{k})$ obtained from solution of Eq. (13) for the ordinary L-O and extraordinary R-X mode are presented in Fig. 2. The $\operatorname{Im}(\mathrm{k})$ was computed for vertically propagating wave modes of $\mathrm{f}=4.65 \mathrm{MHz}$ and magnetic field strength (obtained by 
IGRF model at the altitude of $75 \mathrm{~km})$ and inclination I in the Czech Republic, $\mathrm{I}=66^{\circ}\left(\Theta=24^{\circ}\right)$. The solution of Eq. (13) was subsequently done for different values of $\omega_{p}$ and $v$ to get the plots in Fig. 2. Colors in Fig. 2a, c, and d display values of $\operatorname{Im}(k)$ as a function of $f_{p} / f$ and $v /(2 \pi f)$ for unmagnetized plasma, L-O mode, and R-X mode, respectively. The $\mathrm{R}-\mathrm{X}$ mode has larger values of $\operatorname{Im}(\mathrm{k})$ and hence undergoes larger attenuation than the $\mathrm{L}-\mathrm{O}$ mode; the solution for the unmagnetized plasma $(\boldsymbol{B}=0)$ provides intermediate values of $\operatorname{Im}(\mathrm{k})$. As expected from Eqs. (11) and (12), the $\operatorname{Im}(k)$ increases with $\mathrm{f}_{\mathrm{p}} / \mathrm{f}$ ratio. The dependence of $\operatorname{Im}(k)$ on $v /(2 \pi f)$ is more complicated as is also documented in Fig. $2 b$ that displays $\operatorname{Im}(k)$ for $f_{p} / f=$ const. $\operatorname{Im}(k)$ first increases with increasing $v /(2 \pi f)$ ratio up to a maximum at $v /(2 \pi f)=1, v /(2 \pi f)=1.25$, and $v /(2 \pi f)=0.72$ for the $B=0$ case, L-O mode, and R-X mode, respectively. For higher $v /(2 \pi f)$ ratios, the $\operatorname{Im}(k)$ decreases as the atmosphere starts behaving as neutral gas, rather than a plasma (a situation below the ionosphere). The maxima are sharper for higher $f_{p} / f$ ratios. The shapes of curves for $\boldsymbol{B}=0, \mathrm{~L}-\mathrm{O}$ mode and $\mathrm{R}-\mathrm{X}$ mode are similar. Thus, the simplest case $(\boldsymbol{B}=0)$ described by Eqs. (10)-(11) provides a good idea about the qualitative behavior of $\operatorname{Im}(\mathrm{k})$.

To calculate $\operatorname{Im}(\mathrm{k})$ and attenuation A for waves propagating in a real atmosphere, it is necessary to know how the plasma frequency $f_{p}$, determined by the electron density, and electron-neutral collision frequency change with height. The electron-neutral collision frequency can be estimated by the following formula (Kelley 2009).

$$
v=5.4 \cdot 10^{-16} N_{\mathrm{n}} \sqrt{T_{\mathrm{e}}},
$$

where $N_{n}$ is the density of the neutral particles (in $\mathrm{m}^{-3}$ ), and $T_{e}$ is the temperature of electrons; $N_{n}$ and $T_{e}$ can be obtained from the empirical model of atmospheric composition and temperature NRLMSISE-00 (Picone et al. 2001) and model of international reference ionosphere IRI (Bilitza et al. 2014), respectively. The specific values will be obtained for the locations and times of individual observations. The plasma frequency $\mathrm{f}_{\mathrm{p}}$ in the $\mathrm{F}$ and $\mathrm{E}$ layers can be obtained from electron density profile measured by ionospheric sounders. The electron densities in
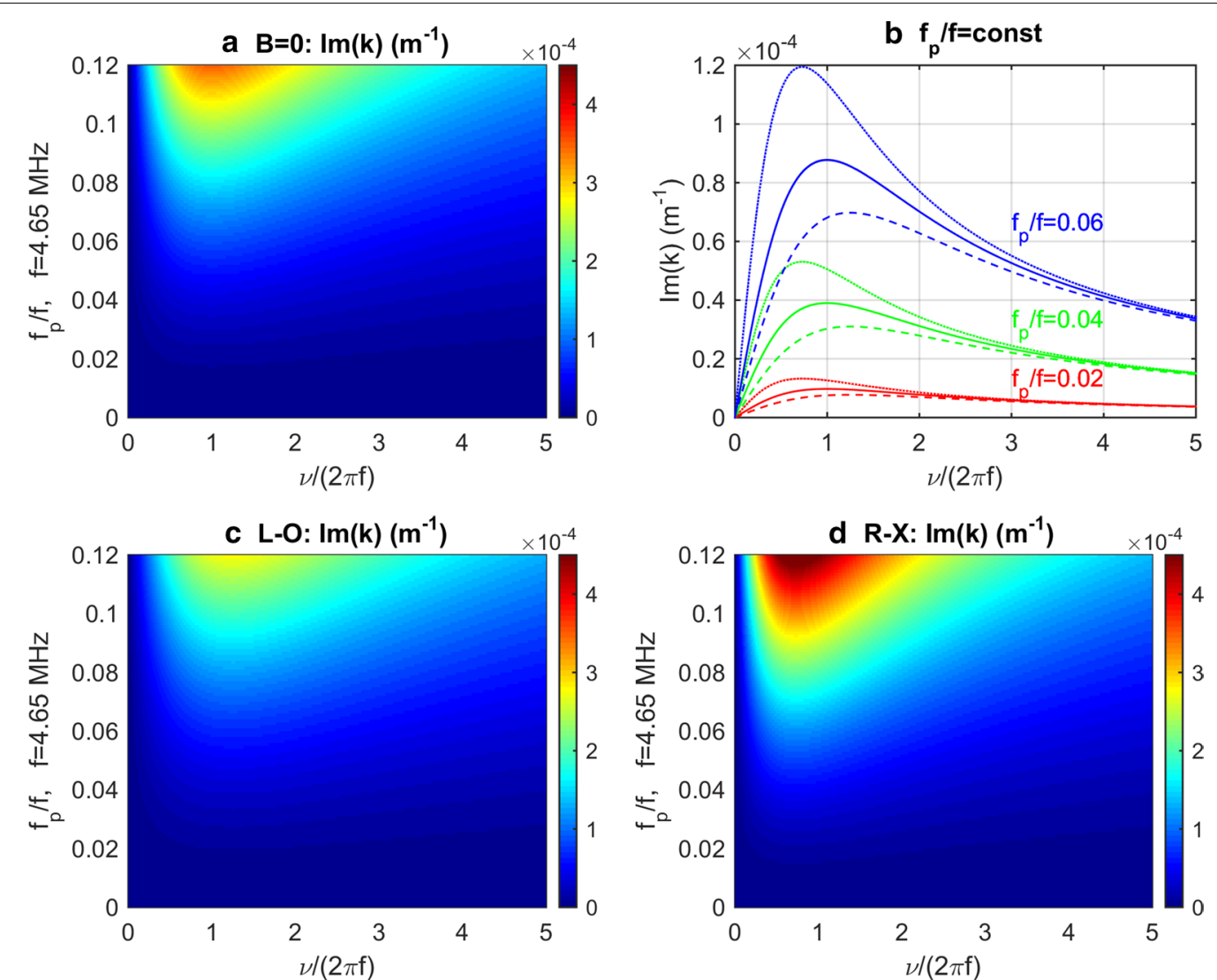

Fig. 2 Imaginary part of wave vector $\operatorname{Im}(k)$ for frequency $f=4.65 \mathrm{MHz}$. a Color-coded values of $\operatorname{Im}(k)$ as a function of $f_{p} / f$ and $v /(2 \pi f)$ for unmagnetized plasma. $\mathbf{b} \operatorname{Im}(k)$ as a function of $\mathrm{v} /(2 \pi f)$ for $\mathrm{f}_{p} / \mathrm{f}=$ const; red for $\mathrm{f}_{\mathrm{p}} / \mathrm{f}=0.02$, green for $\mathrm{f}_{\mathrm{p}} / \mathrm{f}=0.04$, blue for $\mathrm{f}_{\mathrm{p}} / \mathrm{f}=0.06$; unmagnetized plasma by solid, L-O mode by dash, R-X mode by dot-dash. c Color-coded values of $I m(k)$ as a function of $f_{p} / f$ and $v /(2 \pi f)$ for L-O mode. $\mathbf{d}$ Color-coded values of $\mathrm{Im}(\mathrm{k})$ as a function of $\mathrm{f}_{\mathrm{p}} / \mathrm{f}$ and $\mathrm{v} /(2 \pi f)$ for R-X mode 
the D layer (partly also in the E layer), which are important regions for signal attenuation, cannot be directly measured by ionospheric sounders and will be estimated from IRI model at the time just before the solar flare. The estimates of the electron profile downward shift in the D region during $\mathrm{X}$-ray flares are based on the work by Han and Cummer (2010). The changes of measured signal attenuation can be compared with the expected attenuation, based on modeled values of $\mathrm{N}_{\mathrm{n}}$ and $\mathrm{f}_{\mathrm{p}}$.

\section{Satellite data of EUV and X-ray fluxes}

For comparison with the measured Doppler shifts the space environment monitoring (SEM) instruments on geostationary satellite GOES- 15 , located at $135^{\circ} \mathrm{W}$, are used. Specifically, the XRS-EUV (X-Ray and Extreme Ultra-Violet) sensor measuring disk-integrated solar $\mathrm{X}$-ray ( $2 \mathrm{~s}$ cadence) in two channels, ranges of $0.05-$ $0.4 \mathrm{~nm}$ and $0.1-0.8 \mathrm{~nm}$, and EUV fluxes (10 s cadence) in five channels. We have analyzed data from three calibrated EUV channels: A, B, and E covering approximately spectral ranges of 5-15 nm, 25-35 nm (includes Fe-XV at $28.4 \mathrm{~nm}, \mathrm{He}-\mathrm{II}$ at $30.4 \mathrm{~nm}$ ), and 115-127 nm (includes H-Lyman-alpha at $121.6 \mathrm{~nm}$ ), respectively. Only channels $\mathrm{B}$ and $\mathrm{E}$ will be presented further, as for these channels it was possible to compute the time derivatives reliably (time derivative of channel A contained too much of digitization noise).

\section{Observations, case studies}

Solar flares are classified according to X-ray flux in the wavelength range from 0.1 to $0.8 \mathrm{~nm}$. The classification taken from the list available at NASA web page (http:// hesperia.gsfc.nasa.gov/goes/goes_event_listings/) is used in this paper.

Obviously, solar flares can cause SFDs at specific locations only if the Sun's elevation is larger than zero, $\varepsilon>0$. The following examples will demonstrate that the SFDs induced by solar flares can be observed for various solar elevation angles $\varepsilon$ and at different ionospheric heights. The larger $\varepsilon$ and the more rapid increase in EUV flux, the more distinct Doppler shift is observed in the Doppler shift spectrogram. Large EUV and X-ray fluxes can lead to substantial attenuation or even disappearance of the signal owing to radio absorption in the lower ionosphere.

\section{X1.6 event on 22 October 2014, observation in the Czech Republic, solar elevation $\sim 15^{\circ}$}

Figure $3 \mathrm{a}-\mathrm{c}$ displays the Doppler shift spectrograms recorded by three CDSSs in the Czech Republic during $\mathrm{X} 1.6$ event on 22 October 2014 at frequencies $\mathrm{f}=7.04$, 4.65 , and $3.59 \mathrm{MHz}$, respectively. As was mentioned in "Continuous Doppler sounding" section, at least three different sounding paths (transmitted frequencies are mutually shifted by about $4 \mathrm{~Hz}$ ) are used by each CDSS to study propagation of GWs. We will limit here on the sounding paths that correspond to the signals from the transmitters that are located in Pruhonice at about $7 \mathrm{~km}$ distance from the receivers. This proximity makes it possible to observe ground waves (straight horizontal lines in the Doppler shift spectrograms in Fig. $3 \mathrm{a}-\mathrm{c}$ ) and hence to determine reliably the zero Doppler shifts for these signals. SFDs of the received signals are seen at about 14:06 UT (14.1 UT) in all three Doppler shift spectrograms. The solar elevation angle $\varepsilon$ was $\sim 14.9^{\circ}$ at that time (zenith angle $\sim 75.1^{\circ}$ ). Besides the SFD, GWs of period around 15 min are also observed, especially by the CDSS operating at $\mathrm{f}=7.04 \mathrm{MHz}$. It is noticeable that just after the SFD, the signals are strongly attenuated. The attenuation is most obvious for the lowest frequency, $\mathrm{f}=3.59 \mathrm{MHz}$, in accordance with the theory presented in "Attenuation of radio signal in the ionosphere" section. The signal practically disappeared (merged into the noise) for $\sim 20 \mathrm{~min}$ at this frequency. Figure $3 \mathrm{~d}$ presents the plasma frequency profile (given by electron densities) measured by the ionospheric sounder at 14:00 UT (blue solid line), just before the observation of the SFD (the ionogram was manually corrected). There was a sporadic Es layer (foEs $\sim 3 \mathrm{MHz}$ ), seen as straight horizontal line from about $1.5-3 \mathrm{MHz}$ in Fig. 3d. Consequently, there was no information about electron densities between the Es and F2 layer and uncertainties of the true heights displayed in Fig. 3d can be relatively large (about $10-20 \mathrm{~km}$ ). Moreover, the ionospheric sounder does not detect low densities below about $100 \mathrm{~km}$. Therefore, we also display the plasma frequency profile obtained by the IRI-2016 model (dashed red line). The measured reflection heights for ordinary mode are 206, 178, and $154 \mathrm{~km}$ for $\mathrm{f}=7.04,4.65$, and $3.59 \mathrm{MHz}$, respectively. The heights obtained from IRI2016 for the same frequencies are 200, 174, $159 \mathrm{~km}$.

Figure 4 displays X-ray and EUV fluxes measured by GOES-15 satellite (plot a) and their corresponding time derivatives (plot b); the time derivatives of EUV B and $\mathrm{E}$ channels were multiplied by 0.1 to display them in the same plot as the time derivatives of $\mathrm{X}$-ray fluxes in the $0.1-0.8 \mathrm{~nm}$ (red) and 0.05-0.04 (blue) spectral ranges. Figure $4 c$ shows the Doppler shifts $f_{D}$ that correspond to maxima of spectral intensities obtained with $6 \mathrm{~s}$ time resolution from the vertical sounding paths shown in Fig. 3a-c. The Doppler shifts for $\mathrm{f}=7.04,4.65$, and $3.59 \mathrm{MHz}$ are displayed by black, red, and blue, respectively. The positive peaks of $f_{D}$ correspond to rapid increase in electron densities during the rising phase of solar flare ionizing flux. The highest positive peak of $f_{D}$ is observed at the highest sounding frequency $f=7.04 \mathrm{MHz}$ (black curve). However, the positive peaks of $f_{D}$ for $\mathrm{f}=3.59$ and $4.65 \mathrm{MHz}$ are comparable. Thus, the Doppler 

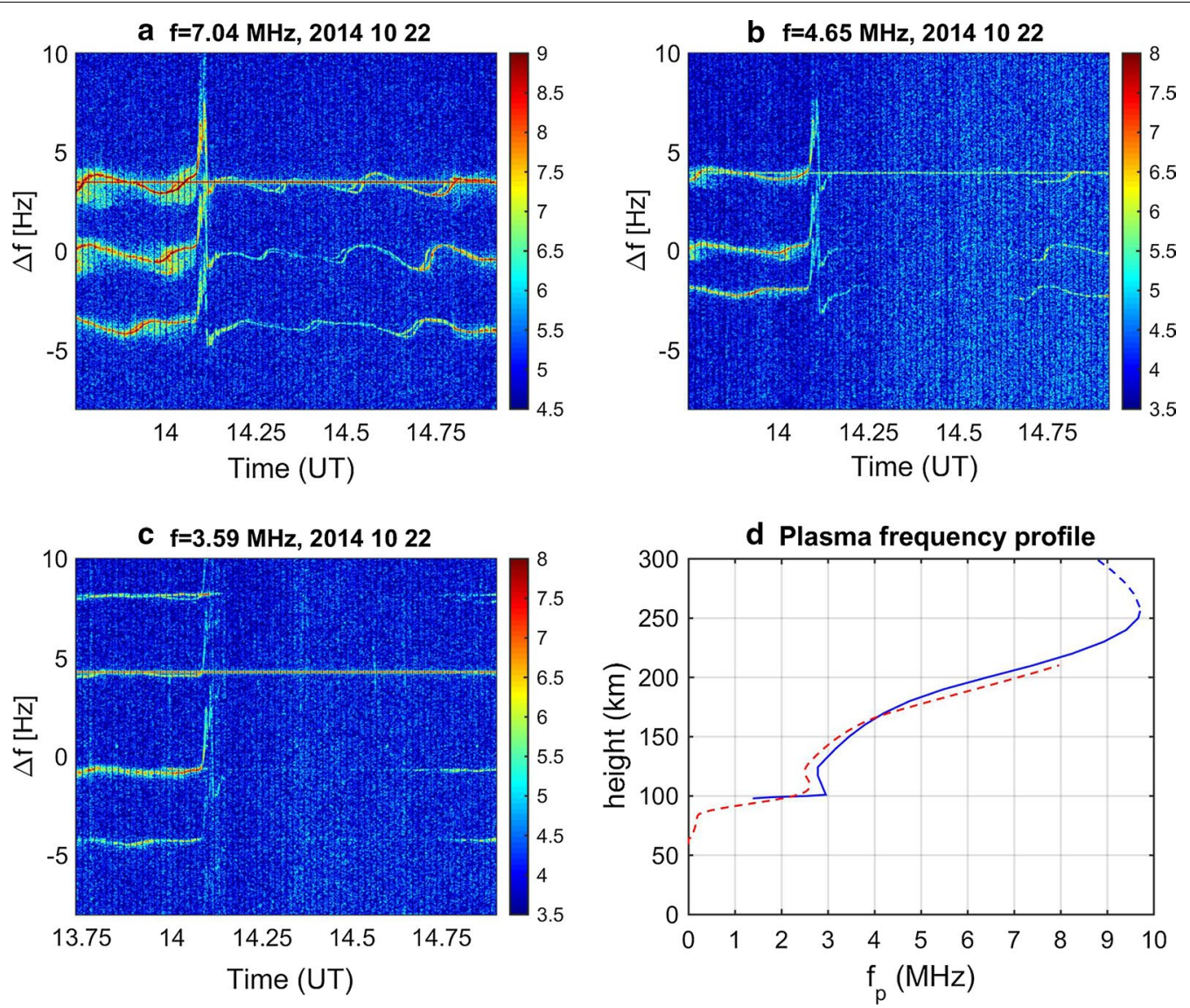

Fig. 3 Spectrograms recorded by the CDSS in the Czech Republic on 22 October 2014 from 13:45 to 14:55 at a 7.04 MHz, b 4.65 MHz, c 3.59 MHz, d Plasma frequency as a function of height obtained from ionospheric sounder (blue) and from IRI-16 model (red) at 14:00 UT

shifts $\mathrm{f}_{\mathrm{D}}$ are not proportional to sounding frequency $\mathrm{f}$ as could be expected from Eq. (3). Possible reasons for that are as follows. First, electron density increases below the reflection level could partly contribute to the observed Doppler shift. The lowest frequency $(3.59 \mathrm{MHz})$ is the most sensitive to such electron density changes below the reflection height as discussed in "Continuous Doppler sounding" section in the text related to Eq. (5). Indeed, the plasma frequency of the Es layer peak (about $3 \mathrm{MHz}$ before solar flare; Fig. 3d) is relatively close to $\mathrm{f}=3.59 \mathrm{MHz}$. Second, various frequencies reflect at different heights and it is well possible that electron density changes are different at different reflection heights. It is difficult to distinguish between these two possibilities. It is likely that both contribute to the observed Doppler shifts. Figure $4 \mathrm{~d}$ presents the virtual plasma velocities $\mathrm{u}_{\mathrm{p}}^{*}$ calculated from the observed $\mathrm{f}_{\mathrm{D}}$ by Eq. (3); the lower sounding frequency $f$, the higher $u_{\mathrm{P}}^{*}$ was observed. For frequencies $\mathrm{f}=4.65$ and $3.59 \mathrm{MHz}, \mathrm{f}_{\mathrm{D}}$ and $\mathrm{u}_{\mathrm{p}}^{*}$ are only shown for limited time intervals as the maxima of spectral intensities could not be reliably determined for most of the time because of low signal-to-noise ratio. Nevertheless, the most important part during the initial phase of SFD is depicted. The negative peaks of $u_{\mathrm{p}}^{*}$ correspond to the peaks of time derivatives of EUV fluxes (magenta and orange curves). The importance of the time derivative of ionizing flux was pointed out in the previous paper by Liu et al. (1996). However, it is shown here with the time resolution on the order of seconds rather than with the time resolution on the order of minutes that was used by Liu et al. (1996). This high-time resolution also made it possible to calculate the time derivative of the measured ionizing flux, which was not done before. In addition, it is shown that the curves of $f_{D}\left(u_{p}^{*}\right)$ better correlate (anti-correlate) with time derivative of EUV fluxes rather than with time derivative of X-ray flux, which was not mentioned by Liu et al. (1996). This is, however, expected as the EUV flux is absorbed at higher altitudes than the X-ray flux that penetrates to $\mathrm{D}$ region (Kelley 2009). Also, the absolute changes of ionizing flux are larger in EUV range than in the X-ray range, though the relative (percentage) changes are much larger in the 

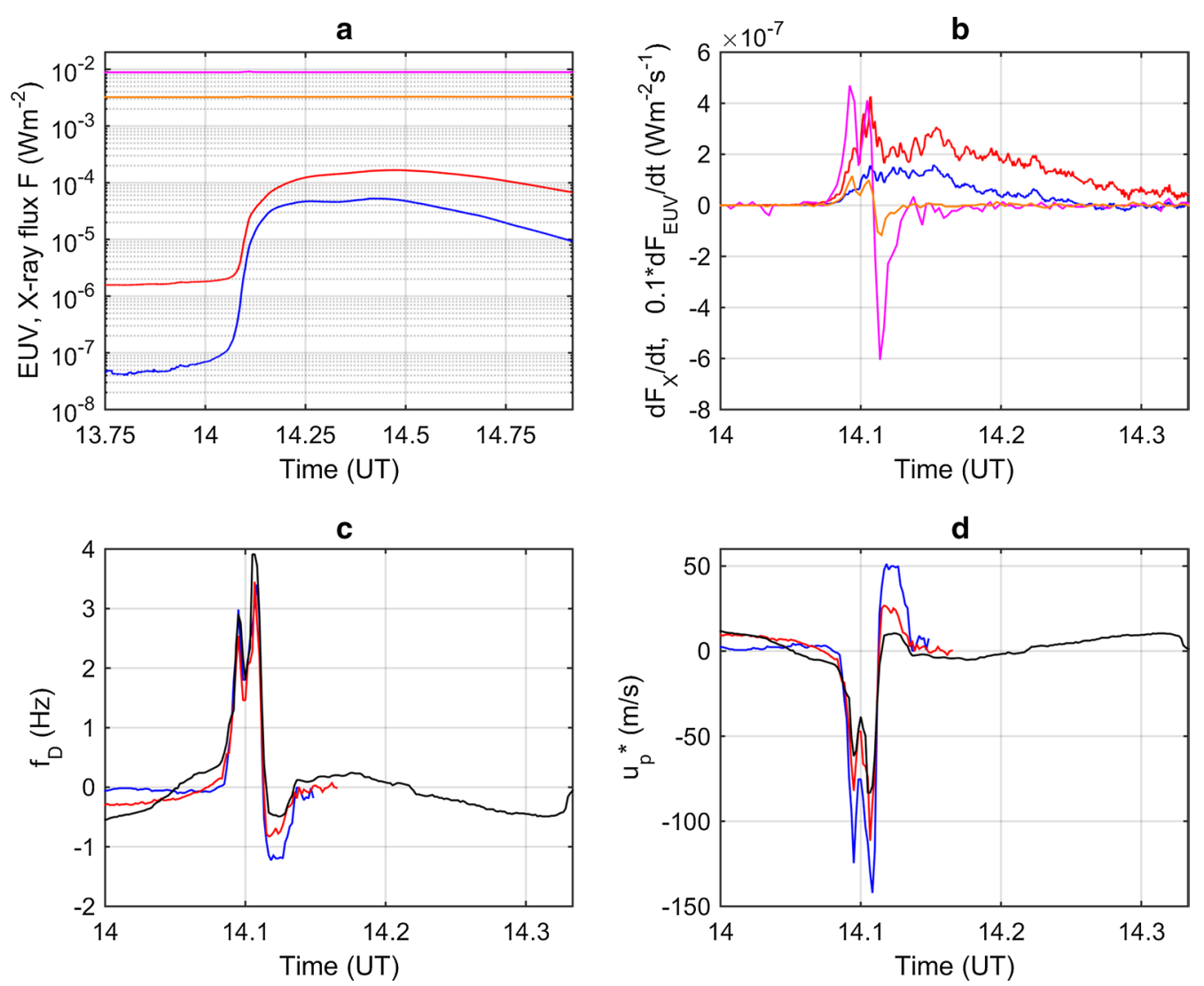

Fig. 4 a lonizing fluxes recorded by GOES-15 satellite on 22 October 2014 from 13:45 to 14:55 UT. X-ray fluxes in the ranges $0.1-0.8 \mathrm{~nm}$ and $0.05-0.4 \mathrm{~nm}$ by red and blue, respectively. EUV H-lyman-alpha flux and EUV flux in the range $25-35 \mathrm{~nm}$ by magenta and orange, respectively. $\mathbf{b}$ Time derivatives of the X-ray fluxes, $\mathrm{dF}_{X} / \mathrm{dt}$, (red for $0.1-0.8 \mathrm{~nm}$, blue for $0.05-0.4 \mathrm{~nm}$ ) and $0.1 \times \mathrm{dF}_{\text {EUV }} / \mathrm{dt}$ of the EUV H-lyman-alpha flux (magenta) and of the $25-35 \mathrm{~nm}$ channel (orange). c Observed Doppler shift at $\mathrm{f}=7.04,4.65$ and $3.59 \mathrm{MHz}$ by black, red, and blue, respectively. $\mathbf{d}$ Virtual plasma velocity up obtained by Eq. (3) for $\mathrm{f}=7.04,4.65$ and $3.59 \mathrm{MHz}$ by black, red, and blue, respectively

$\mathrm{X}$-ray range. The fact that the fine structure and timing of $\mathrm{f}_{\mathrm{D}}\left(\mathrm{u}_{\mathrm{P}}^{*}\right)$ better correspond with time derivative of EUV flux rather than with X-ray flux that penetrates the D region also supports the assumption that the main contribution to the observed Doppler shift comes from electron density changes at higher altitudes (likely reflection regions) than from electron density changes in the D layer, which is mainly responsible for the signal attenuation.

The virtual plasma velocities $\mathrm{u}_{\mathrm{p}}^{*}$ make it possible to estimate electron density changes during the solar flare. The electron density changes are shown in Fig. 5, together with the electron density gradient $\partial \mathrm{N} / \partial \mathrm{z}$ (Fig. 5a) used for their calculations. The loop just below the frequency of $3 \mathrm{MHz}$ in Fig. 5a is caused by the valley between Es and $\mathrm{F}$ layer and corresponds to the ionogram (true height profile) presented in Fig. 3d. Figure $5 \mathrm{~b}$ presents the height change $\Delta \mathrm{h}$ calculated by Eq. (4). Figure $5 \mathrm{c}$ displays the absolute density changes $\Delta \mathrm{N}$ calculated by Eq. (7). Finally, Fig. $5 \mathrm{~d}$ shows the relative density changes $\Delta \mathrm{N} /$ $\mathrm{N}_{0}$, related to values of electron densities at 14:00 UT obtained from the plasma frequency profile presented in Fig. 3d. The values correspond to reflection heights of $7.04,4.65$, and $3.59 \mathrm{MHz}$ and are displayed by black, red, and blue, respectively. The computation of $\Delta \mathrm{N}$ was started at 14:04 UT since at that time the X-ray and EUV fluxes started to rise (Fig. 4a, b). The nonzero value of $u_{p}^{*}$ at 14:04 UT (Fig. 4d), especially for $7.04 \mathrm{MHz}$, is caused by the presence of GWs. The presence of GW can be recognized from the phase (time) shifts between fluctuations observed on different sounding paths (Fig. 3a). Fluctuations caused by GWs limit the accuracy of $\Delta \mathrm{N}$ calculation. However, because the SFD caused by the solar flare clearly dominates over the Doppler shift induced by the GWs, the error introduced by GWs is probably smaller than the uncertainty arising from the uncertainty in $\partial \mathrm{N} / \partial \mathrm{z}$ measurement. Although the values of $\mathrm{u}_{\mathrm{p}}^{*}$ calculated by Eq. (3) were largest for the lowest frequency, the absolute density changes $\Delta \mathrm{N}$ obtained by Eq. (7) were larger for higher frequencies reflecting at higher reflection heights, because of larger $\partial \mathrm{N} / \partial \mathrm{z}$ values. However, the 

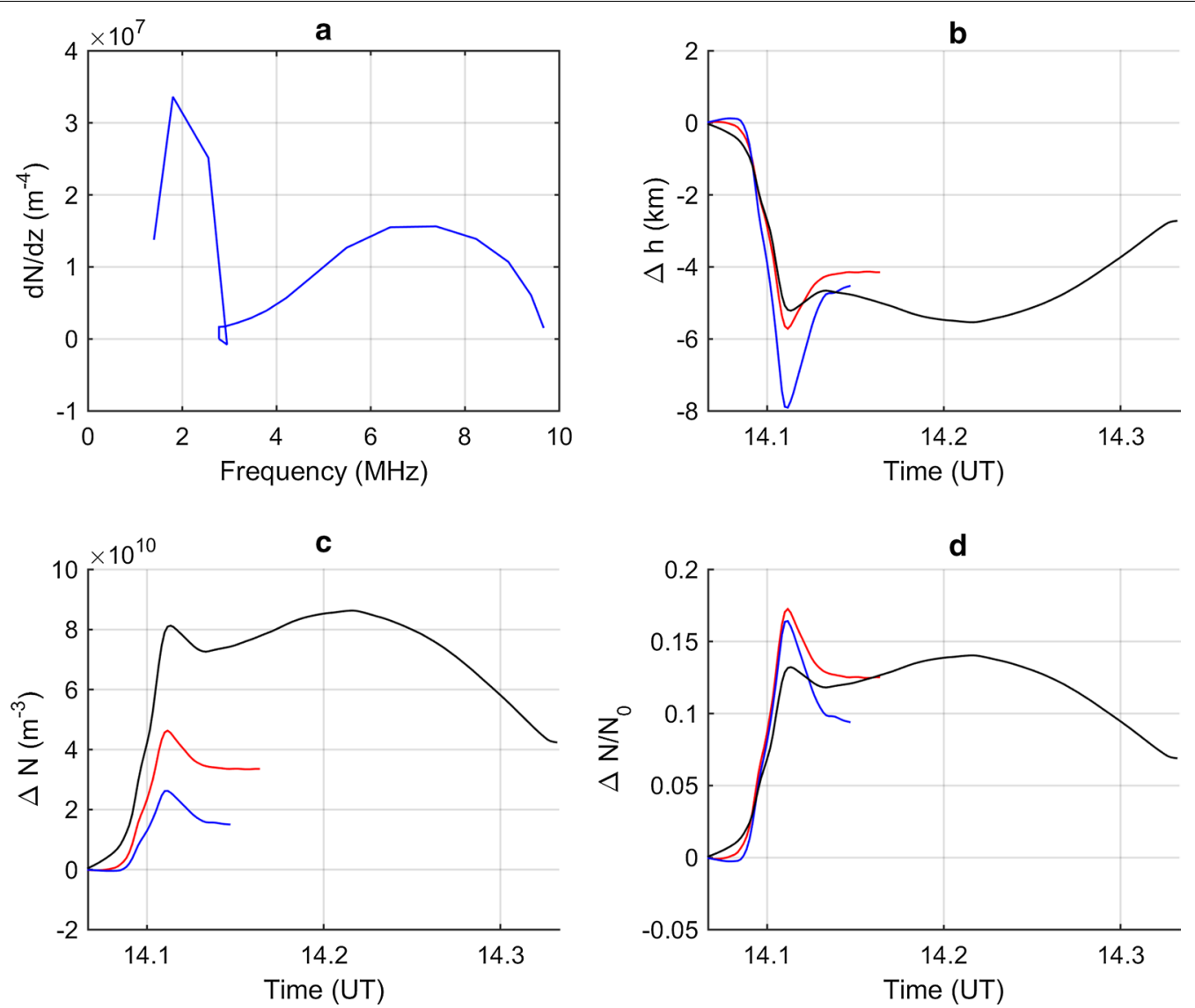

Fig. 5 Electron density gradient and electron density changes. a Electron density gradient as a function of plasma frequency, $\mathbf{b}$ fluctuations of reflection heights calculated by Eq. (4) for $\mathrm{f}=7.04,4.65$, and $3.59 \mathrm{MHz}$ by black, red, and blue, respectively, c electron density change $\Delta \mathrm{N}$ calculated by Eq. (7) at the reflection heights for $\mathrm{f}=7.04,4.65$ and $3.59 \mathrm{MHz}$ by black, red, and blue, respectively. $\mathbf{d}$ Relative electron density change related to the electron density at 14:00 UT on 22 October 2014 (Fig. 3d)

relative density changes were larger for lower reflection heights. The relative density changes between the heights of about $155-205 \mathrm{~km}$ were around $15 \%$ (Fig. $5 \mathrm{~d}$ ). The second flat peak in Fig. $5 \mathrm{~d}$ for $\mathrm{f}=7.04 \mathrm{MHz}$ at around 14:13 UT (14.22 UT) results from fluctuations caused by shortperiod GWs, seen also in Figs. 3a and 4c.

It should be stressed that the electron density changes during the solar flare cannot be reliably determined from ionograms. The signals from the ionospheric sounders experience the same attenuation as the signals transmitted by the CDSS. Consequently, a small signal-to-noise ratio made it impossible to detect the signals of frequencies lower than about 4.1 MHz during this solar flare as is documented in Fig. 6 that shows a sequence of ionograms recorded just before the solar flare at 14:00 UT (a) and during the solar flare at 14:15 (b). The absence of low frequencies in ionograms owing to strong signal attenuation during the solar flare might lead to large errors (uncertainties) in determining the true heights of electron densities.
It is useful to estimate the electron density changes in the lower ionosphere that lead to the observed attenuation in Fig. 3a and b (the measurement at $3.59 \mathrm{MHz}$ shown in Fig. 3c will not be considered as the reflected signal disappeared at this frequency, merged with the noise, and only ground waves could be observed). Figure 7a displays the electron-neutral collision frequency obtained by Eq. (14) for the Czech Republic on 22 October 2014 at 14:00 UT using the NRLMSISE-00 and IRI2016 models for $\mathrm{N}_{\mathrm{n}}$ and $\mathrm{T}_{\mathrm{e}}$ values. The electron density profile before the solar event, obtained at 14:00 UT, is shown by the blue curve in Fig. 7b. The displayed profile is a combination of the measured and modeled values. For electron densities corresponding to plasma frequency 1.4 $\mathrm{MHz}$ and higher, the profile measured by the digital portable sounder (digisonde) located in Pruhonice (Figs. 3d, 6a) was used. For lower plasma frequencies and heights below the Es layer (around $100 \mathrm{~km}$ ), no signal was detected by the digisonde and the IRI2016 model was applied to obtain the electron densities. The imaginary 

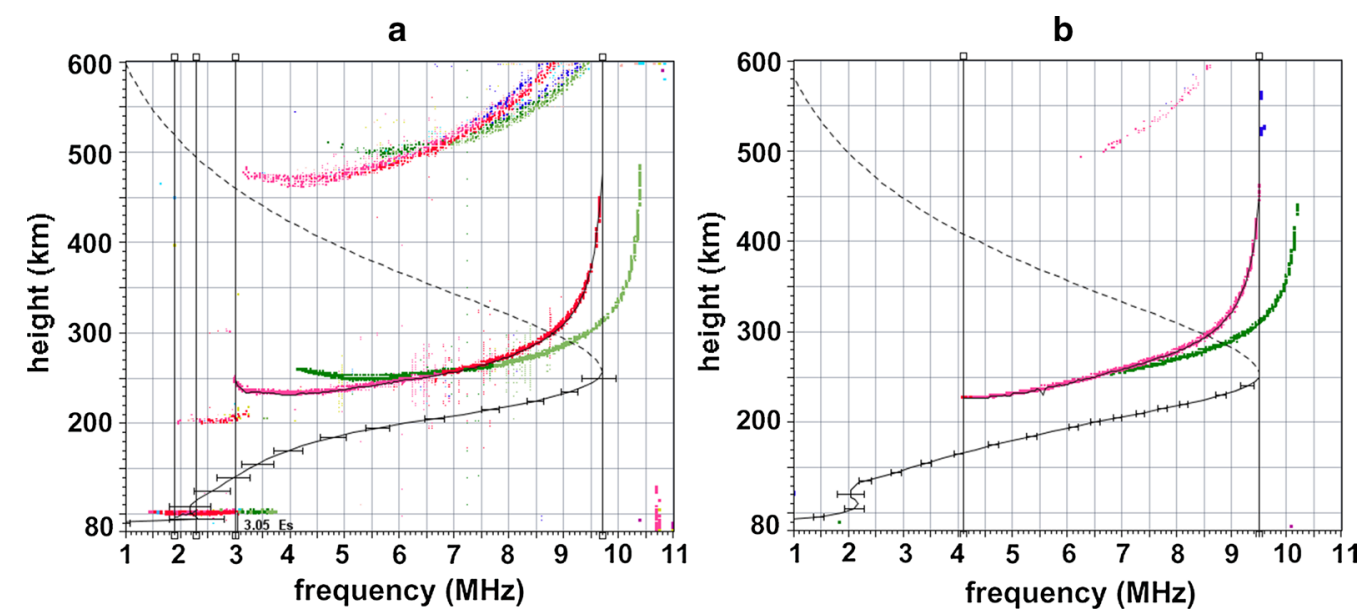

Fig. 6 lonograms recorded by DPS-4 in Pruhonice just before the X-ray flare at 14:00 UT a and during the X-ray flare at 14:15 UT, b on 22 October 2014. Virtual reflection heights of ordinary L-O mode waves are by red, virtual reflection heights of extraordinary R-X mode waves are by green, and true reflection heights are by black
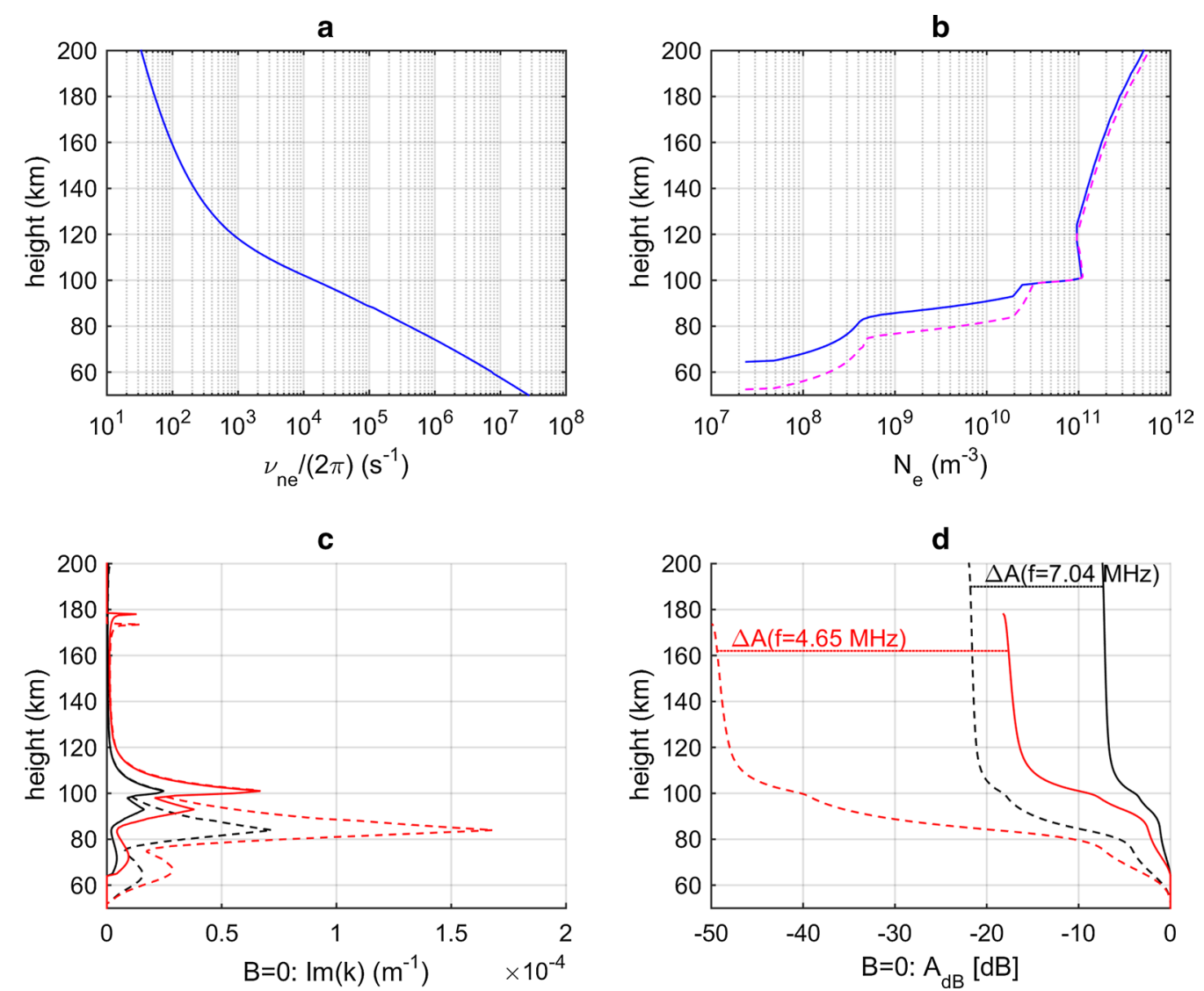

Fig. 7 Estimating attenuation in the Czech Republic on 22 October 2014. Solid lines represent modeled values before solar flare event at 14:00 UT and dashed lines the values during solar flare event $\mathbf{a}$ electron-neutral collision frequency $\mathrm{V} /(2 \pi)$ as a function of height. $\mathbf{b}$ Electron density as function of height. $\mathbf{c}$ Imaginary part of wave vector as a function of height for $\mathrm{B}=0$ and $\mathrm{f}=7.04 \mathrm{MHz}$ (black) and $\mathrm{f}=4.65 \mathrm{MHz}$ (red). $\mathbf{d}$ Cumulative attenuation $\mathrm{A}$ in $\mathrm{dB}$ considering propagation up and down for $\mathrm{f}=7.04 \mathrm{MHz}$ (black) and $\mathrm{f}=4.65 \mathrm{MHz}$ (red) 
parts of wave vectors $\operatorname{Im}(\mathrm{k})$ for unmagnetized plasma $(B=0)$ as functions of height are shown by solid lines in Fig. 7c (black for $\mathrm{f}=7.04 \mathrm{MHz}$ and red for $\mathrm{f}=4.65 \mathrm{MHz}$ ). It is seen that $\operatorname{Im}(\mathrm{k})$ has a minor local maximum at heights between 60 and $80 \mathrm{~km}$. This local maximum is caused by similar values of collision frequency $v /(2 \pi)$ and sounding frequency $\mathrm{f}$ (see Fig. 2 and related text). The larger maxima of $\operatorname{Im}(\mathrm{k})$ at heights between $80 \mathrm{~km}$ and Es layer, and at the height of Es layer are caused by rapidly increasing electron density and hence by the rapid increase in $f_{p} / f$ ratio that dominates the decrease in $v /$ $(2 \pi f)$ at these heights. The corresponding attenuations calculated by Eq. (9) are displayed by solid lines in Fig. 7d.

The electron density profile during the solar flare, shown in Fig. 7b by dashed magenta, was not measured. It was roughly estimated as follows: (a) The lowest part of the original profile (solid blue) up to $83 \mathrm{~km}$ was shifted downward by $12 \mathrm{~km}$. The value of this downward shift is based on the work by Han and Cummer (2010), and references therein, who reported the lowering of reflection height for atmospherics in D layer by about $6 \mathrm{~km}$ if the X-ray flux in the $0.1-0.8 \mathrm{~nm}$ channel increased by a factor of 10 . They found that the decrease in the reflection height depends practically linearly on the logarithm of X-ray flux. The X-ray flux in this channel increased approximately 100 times in our case (Fig. 4a). (b) The height of the Es layer around $100 \mathrm{~km}$ was considered unchanged during the solar flare. This assumption could not be proved experimentally as the minimum frequency detectable in the ionogram is larger than the critical frequency of Es (Fig. 6) during the X-ray flare. However, the height of Es usually does not change rapidly. Also, the rapid change of the height of Es is not expected as the generally accepted main mechanism responsible for the formation of the Es layer is the wind shear (Mathews 1998; Haldoupis 2012). It is more complicated to estimate the change of electron density in the Es layer, which likely increases during the X-ray flare because of the enhanced ionizing flux. We will assume for simplicity that the relative increase in the Es density is the same as the relative increase in electron densities in the layers above that can be estimated from the Doppler shifts. This might be not quite correct and leads to a certain uncertainty. Nevertheless, the influence of this uncertainty on the cumulative attenuation is not dominant because of the relatively narrow height extent of the Es layer as seen in Fig. 7. (c) The profile in the F layer was lowered by $\Delta \mathrm{h}=4.5 \mathrm{~km}$ as estimated from Fig. 5b. It is reminded that there is a close relation between the height decrease and electron density increase at a specific height (Eqs. 4, 6, 7). To ensure that there is an electron density increase $\Delta \mathrm{N}$ also at regions with negative electron density gradient, mainly above the Es layer, the sign of $\Delta \mathrm{h}$ was changed in that region.
It should be noted that the changes of electron densities above $\sim 110 \mathrm{~km}$ and especially in the $\mathrm{F}$ layer have only negligible influence on the imaginary part of wave vector and hence on the attenuation. (d) The downward shift of the most critical and important part between $83 \mathrm{~km}$ and Es layer (in original profile) was adjusted so that the relative changes of attenuations would correspond with the observed changes presented in Fig. 3a and b. A rough agreement between the observed and simulated changes $\Delta \mathrm{A}_{\mathrm{dB}}$ was obtained for the downward shift of $9 \mathrm{~km}$ for this part of the profile. The corresponding imaginary parts of $\operatorname{Im}(\mathrm{k})$ and attenuations are shown by dashed lines in Fig. 7c and d, respectively.

It should be noted that the exact treatment of attenuation and more sophisticated comparison between experiment and modeling would require distinction between $\mathrm{R}-\mathrm{X}$ and L-O mode. The current continuous Doppler sounding does not distinguish the R-X and L-O mode. Also, the downward shift of electron density profile by constant values in a few specific height intervals is a simplification. Measurements operating at significantly different frequencies (dominant attenuation at different heights) could provide further insight into the behavior of D layer dynamics at different heights. Nevertheless, even this simple approach provides a basic idea about the electron density changes and altitudes at which the attenuation dominates. It is partly based on available models, and it is roughly consistent with measurements and previous studies.

\section{M7.9 event on 25 June 2015, observation in Taiwan, solar elevation $\sim 32^{\circ}$}

An example of another distinct SFD event accompanied with extreme attenuation is summarized in Fig. 8 that shows X-ray and EUV fluxes (Fig. 8a) and their time derivatives (Fig. 8b) during M7.9 event that occurred on 25 June 2015 around 08:15 UT. The ionospheric response as observed by CDSS located in Taiwan is presented in Fig. 8c. Figure 8d shows the virtual plasma velocity $u_{p}^{*}$ obtained by Eq. (3) from the observed Doppler shift. The virtual velocity was evaluated only up to the moment when it was impossible to find distinct maxima of spectral intensities for specific sounding paths (transmitter-receiver pairs) in the Doppler shift spectrogram as the received signals merged with noise because of large attenuation. Similarly, as in the example of X1.6 event from the Czech Republic, the maximum of Doppler shift (negative maximum of $\left.u_{p}^{\prime \prime}\right)$ occurs at the time when the derivative of EUV flux $\mathrm{dF}_{\mathrm{EUV}} / \mathrm{dt}$ is maximum. The Doppler shift and $u_{\mathrm{p}}^{*}$ are around zero at the maximum of ionizing flux. The Doppler shift correlates better with $\mathrm{dF}_{\mathrm{EUV}} / \mathrm{dt}$ than with $\mathrm{dF}_{\mathrm{X}} / \mathrm{dt}$ as expected and also observed for the 22 October 2014 event in the 

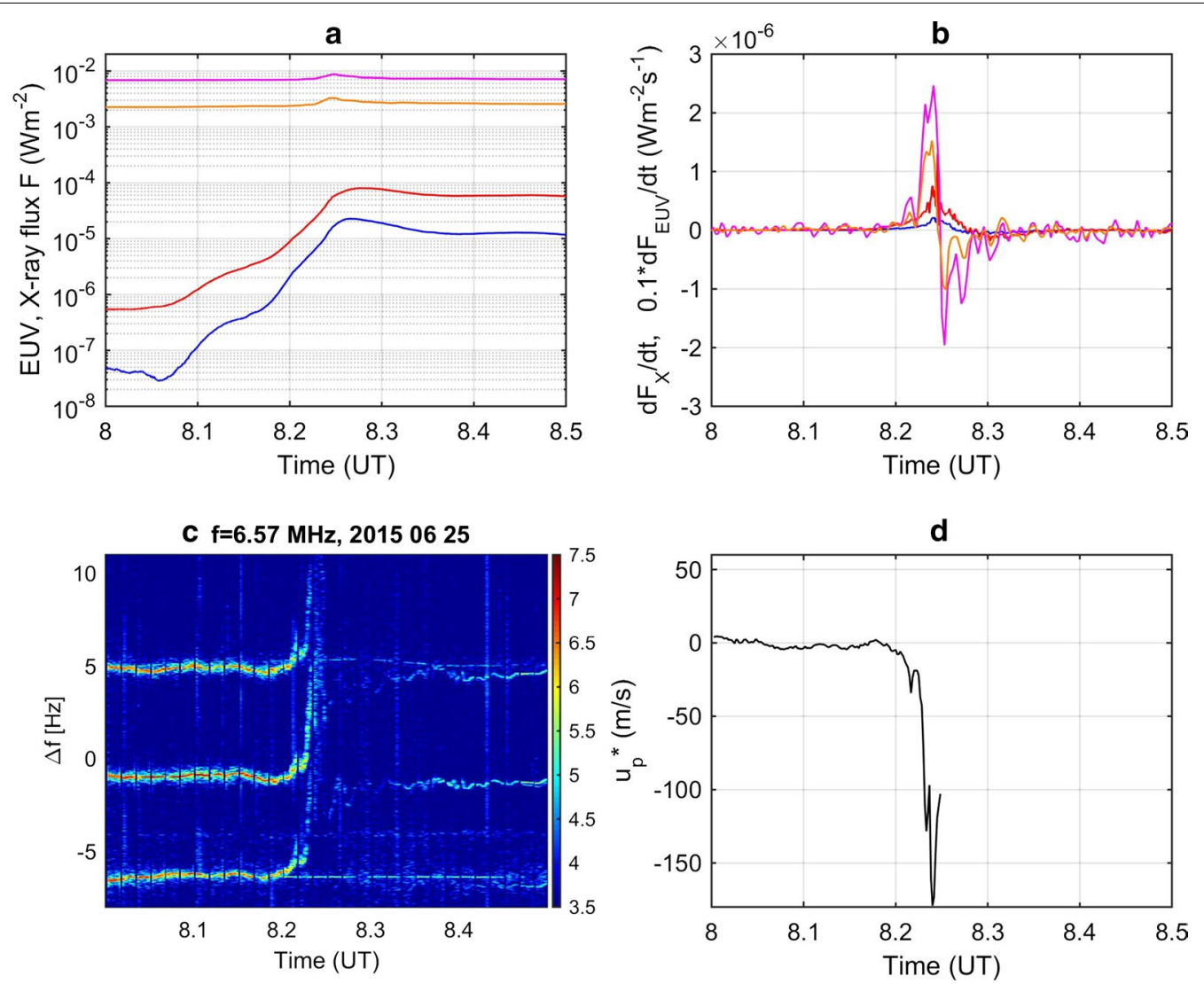

Fig. 8 X-ray event on 25 June 2015 and its ionospheric response. a X-ray fluxes in the ranges $0.1-0.8 \mathrm{~nm}$ and $0.05-0.4 \mathrm{~nm}$ by red and blue, respectively, EUV (lyman H alpha) flux by magenta and EUV flux in the range $25-35 \mathrm{~nm}$ by orange recorded from 08:00 to 08:30 UT. b Time derivatives of the X-ray fluxes, $\mathrm{dF}_{X} / \mathrm{dt}$, (red for $0.1-0.8 \mathrm{~nm}$, blue for $0.05-0.4 \mathrm{~nm}$ ) and $0.1 \times \mathrm{dF}_{\text {EUV }} / \mathrm{dt}$ of the EUV H-lyman-alpha flux (magenta) and of the 25-35 nm channel (orange). c Spectrogram recorded by CDSS in Taiwan from 08:00 to 08:30 UT. d Virtual plasma velocity up obtained by Eq. (3) for $\mathrm{f}=6.57 \mathrm{MHz}$

Czech Republic (In "X1.6 event on 22 Oct 2014, observation in the Czech Republic, solar elevation $\sim 15^{\circ}$ " section). The true reflection height of the CDSS was around $250 \mathrm{~km}$ in this case as was estimated from an ionogram recorded by ionospheric sounder located in Taiwan. The ionograms obtained before the X-ray flare (at 08:00 UT) and during the flare (at 08:20 UT) are shown in Fig. 9. Figure 9 also documents that echoes at lower frequencies are not detected (received) during solar flare because of attenuation; the echo trace starts at $\sim 7 \mathrm{MHz}$ in the ionogram at 08:20 UT (16:20 LT).

The ionospheric response for M7.9 X-ray flare on 26 June 2015 is similar or even larger than for the X1.6 event on 22 October 2014. There are two likely reasons. First, the local solar elevation $\varepsilon$ is larger for the M7.9 event $\left(\varepsilon \sim 31.9^{\circ}\right)$ than for X1.6 event $\left(\varepsilon \sim 14.9^{\circ}\right)$. Second, the flux derivative $\mathrm{dF}_{\mathrm{EUV}} / \mathrm{dt}$ is larger in the case of M7.9 event than in the case of X1.6 event, which contributes to the larger Doppler shift than that observed in the case of X1.6 event.
Another example of ionospheric response to X-ray event, namely to X2.7 flare observed in the ionosphere over Taiwan on 5 May 2015 around 22:10 UT ( 06:10 LT) was given in the paper reviewing the observation by international network of CDSS by Laštovička and Chum (2017). The corresponding figure can be found in that paper. Here, we will only mention that the ionospheric response was relatively small; maximum Doppler shift was around $1.5 \mathrm{~Hz}$, and the signal remained above the noise background all the time, though attenuated, because of low solar elevation, $\varepsilon$ was $\sim 10.2^{\circ}$.

\section{M1.3 and C8.5 events on 7 August 2016, observation in Tucumán, solar elevation $\sim 42^{\circ}$}

As a contrast to the previous examples, Fig. 10a shows a sequence of relatively weak X-ray solar flares; M1.3 event that peaked approximately at 14:44 UT was followed by C8.5 event around 15:09 UT. Ionospheric response, namely, the Doppler shifts associated with these X-ray flares, could be easily unnoticed in the CDSS record 

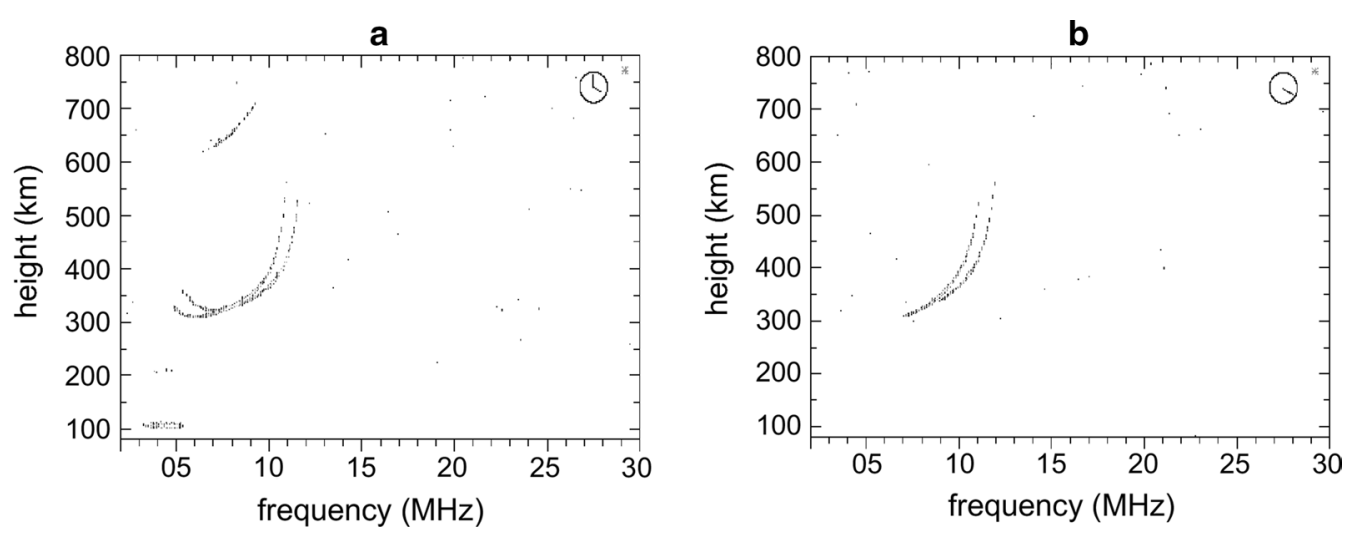

Fig. 9 lonograms recorded in Taiwan on 25 June 2015 at a 08:00 UT (16:00 LT) and b 08:20 UT (16:20 LT)
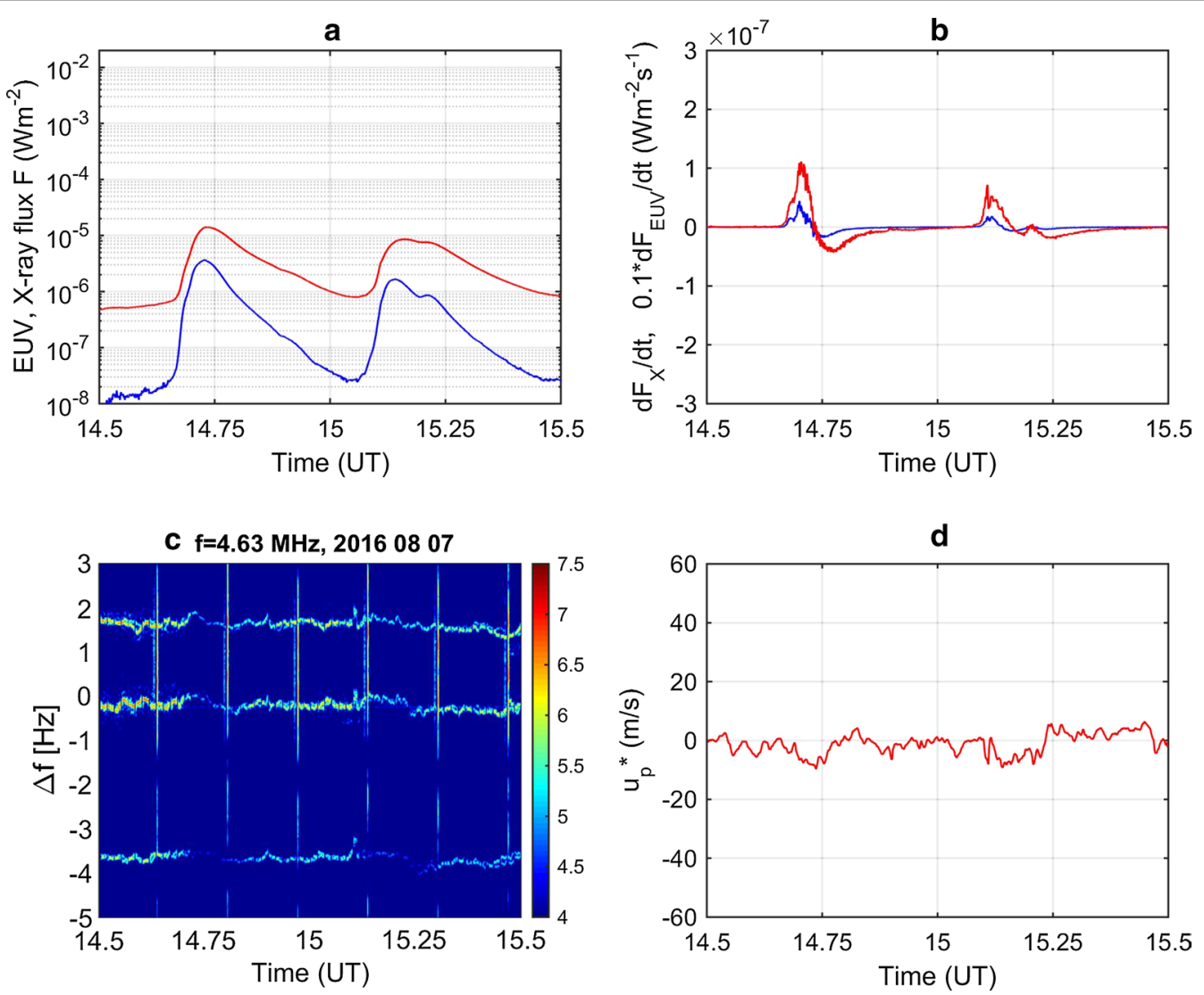

Fig. 10 X-ray events on 7 August 2016 and their ionospheric responses. $\mathbf{a}$ X-ray fluxes in the ranges $0.1-0.8 \mathrm{~nm}$ and $0.05-0.4 \mathrm{~nm}$ by red and blue, respectively, recorded from 14:30 to 15:30 UT. b Time derivatives of the X-ray fluxes, $\mathrm{dF}_{x} / \mathrm{dt}$, (red for $0.1-0.8 \mathrm{~nm}$, blue for $0.05-0.4 \mathrm{~nm}$ ). c Spectrogram recorded by CDSS in Tucumán from 14:30 to 15:30 UT. d Virtual plasma velocity up obtained by Eq. (3) for $\mathrm{f}=4.63 \mathrm{MHz}$

obtained in Tucumán from 14:30 to 15:30 UT (Fig. 10c) as they are comparable with amplitudes of background activity of acoustic gravity waves. The narrow vertical lines observed every $10 \mathrm{~min}$ in Doppler shift spectrogram represent electromagnetic interference (EMI) with nearby ionospheric sounder that measures in 10-min interval. The solar elevation angle was about $40.3^{\circ}$ and $43.1^{\circ}$ during the M1.3 and C8.5 events, respectively. The 
EUV flux is not shown because its changes (time derivative) were small and did not exceed the noise.

Unlike the Doppler shift, the attenuation of the received signal is clearly visible during the time intervals of enhanced X-ray fluxes. It is interesting to compare the attenuation measured by CDSS with attenuation of galactic radio noise measured by riometer, which has been operating in Tucumán at frequency of $38.2 \mathrm{MHz}$ since 2016. Figure 11a shows relative attenuation measured by CDSS operating at $4.63 \mathrm{MHz}$; the received power was evaluated as the mean value during $1 \mathrm{~min}$ time intervals to minimize the noise. The solid blue curve represents values obtained after averaging from all three working sounding paths (transmitter-receiver pairs), whereas the dashed lines mark attenuation for individual paths. The time intervals contaminated by EMI with nearby ionospheric sounder are not displayed. To compute the relative attenuation in $\mathrm{dB}$, the received power was compared with its median value. The enhanced attenuations (local power minima around 14:45 UT and 15:13
UT) correspond well with the enhanced X-ray fluxes in Fig. 10a. The relative attenuation obtained by riometer is shown in Fig. 11b. The solid black curve shows the relative attenuation obtained on 7 August 2016. The curves of attenuations measured by CDSS and riometer look very similar; however, the attenuation measured by CDSS is larger as the CDSS operates at lower frequency than the riometer and because the CDSS's sounding signal passes the lower ionosphere two times (propagating up and down). If we only investigate the relative changes and not the absolute values, it seems that the attenuation of Doppler signal returns to pre-flare values faster than the attenuation obtained by riometer. To investigate if there is no systematic trend in riometer attenuation during the displayed time interval, the quiet day curve (QDC) (Nishino et al. 2002; Moro et al. 2012) was computed as the median of daily curves obtained for 29-day interval centered at 7 August 2016 and subtracted from the measurement on 7 August 2016. The resulting curve (difference between current attenuation and QDC) is displayed

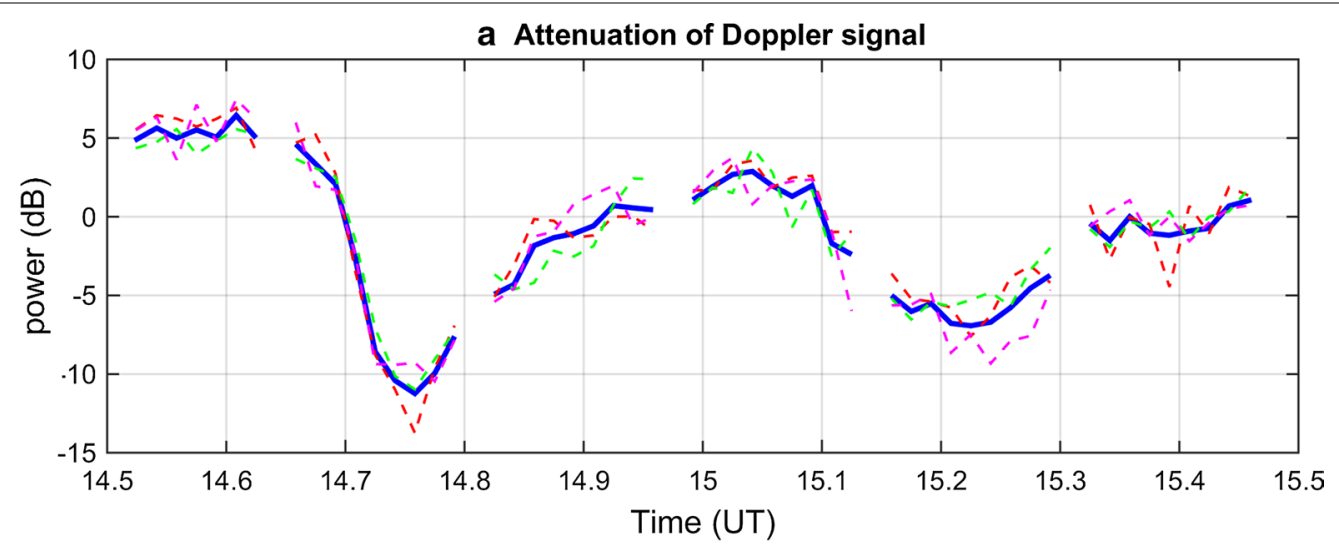

b Riometer output for $\mathbf{2 0 1 6 / 0 8 / 0 7}$

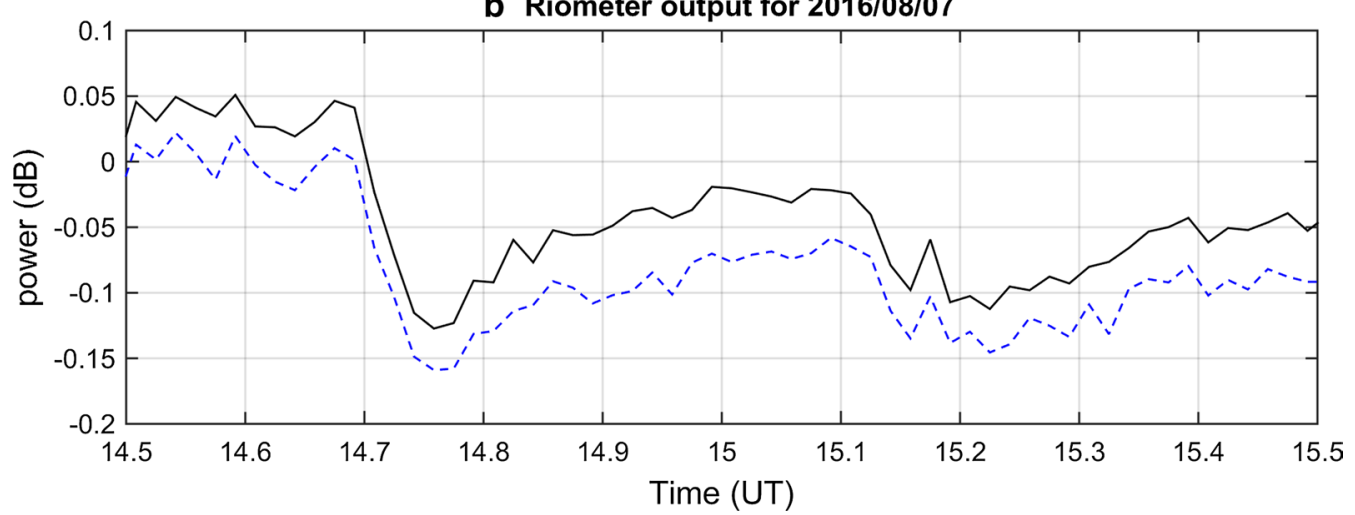

Fig. 11 Relative attenuation of Doppler signals at 4.63 MHz measured in Tucumán on 7 August 2016 during M1.3 and C8.5 X-ray solar flares from 14:30 to 15:30 UT. a Attenuation of Doppler signal, solid blue averaged over three sounding paths, dashed for individual sounding paths. $\mathbf{b}$ Attenuation measured by nearby riometer at $38.2 \mathrm{MHz}$, solid black only for 7 August 2016, dashed after subtracting the quiet day curve (QDC) obtained from 1 month interval 
by dashed line in Fig. 11b. It is obvious that the slower relaxation of power measured by riometer cannot be explained by systematic trend in the power measured by riometer at this time period as QDC (not shown) exhibits almost no trend in the time interval from 14:30 to 15:30 UT.

Figure 12 shows a sequence of ionograms taken in Tucumán just before (at 14:40 UT) and during (at 14:50 UT) the M1.3 event. It is obvious that disappearance of lower frequencies in the ionogram owing to the enhanced signal absorption and decrease in signal-to-noise ratio is also observed for relatively weak X-ray flares; the Es layer observed at 14:40 UT is not detected at 14:50 UT (it is again detected at 15:00 UT, not shown). The estimated true height of reflection for $\mathrm{f}=4.63 \mathrm{MHz}$ is about $200 \mathrm{~km}$; again the uncertainty is relatively large (rough estimate $\sim 20 \mathrm{~km}$ ) because of the complicated character of the ionogram; note that regions between $\mathrm{E}$ and $\mathrm{F} 1$ and F1 and F2 layers cannot be directly measured.

\section{Discussion and future plans}

The previous result by Liu et al. (1996) that the Doppler shifts associated with X-ray solar flares are controlled by the time derivative of ionizing flux rather than by the flux itself was confirmed purely on experimental basis. The paper by Liu et al. (1996) was mainly based on simulations, their time resolution of presented experimental examples did not allow to unambiguously distinguish whether the Doppler shifts correspond better with ionizing flux or with its time derivative and indirect arguments were used. The time resolution provided in the current study ( $6 \mathrm{~s}$ for Doppler shift measurements and $10 \mathrm{~s}$ for the EUV flux) made it possible to clearly show experimentally that the Doppler shift is associated with the time derivative of ionizing flux. Thus, the time at which the Doppler shift is maximum does not correspond with the time of maximum of ionizing flux. In addition, it was shown that it is better to use the time derivative of EUV flux rather than the time derivative of $\mathrm{X}$-ray flux to get the best mutual timing because the EUV flux dominates the ionization at the heights of Doppler shift measurements, which is usually $\mathrm{F}$ layer. The $\mathrm{X}$-ray flux mostly penetrates deeper, and is mainly responsible for the ionization in the $\mathrm{D}$ layer and hence for the attenuation of the radio waves. The attenuation correlates well with the ionizing X-ray flux as can be seen from comparison of Figs. 10a and 11. On the other hand, the rate of electron density change and hence the Doppler shift depends on the time change of the ionizing flux. If the ionizing flux does not change, then loss processes start balancing the production rate and the Doppler shift approaches zero. More precisely, processes such as plasma transport, acoustic gravity waves, etc., become dominant factors that are responsible for the observed Doppler shifts. The precise timing between Doppler shift $\mathrm{f}_{\mathrm{D}}$ and $\mathrm{dF}_{\mathrm{EUV}} / \mathrm{dt}$ or $\mathrm{dF}_{\mathrm{X} \text {-ray }} / \mathrm{dt}$ changes from event to event. The maximum of $\mathrm{f}_{\mathrm{D}}$ usually corresponds to the maximum of $\mathrm{dF}_{\mathrm{EUV}} /$ $\mathrm{dt}$ within about $20 \mathrm{~s}$. The maximum of $\mathrm{dF}_{\mathrm{X} \text {-ray }} / \mathrm{dt}$ might be shifted from $\max \left(\mathrm{f}_{\mathrm{D}}\right)$ by $1-2 \mathrm{~min}$. Certain differences between the timing of EUV and X-ray flux arise from different locations of generation. EUV flux is usually produced in the solar chromosphere, whereas the X-ray flux usually originates from the solar corona (Smith and Gottlieb 1974). It is interesting to note in this respect that the time derivative of the soft X-rays measured by GOES is often used to estimate the time evolution of hard X-rays (above $10 \mathrm{keV}$ ), a so called Neupert effect (Veronig et al. 2005). It should also be noted that the total ionizing flux $F_{I}$ has to be considered to investigate the time shifts between $\max \left(\mathrm{dF}_{\mathrm{I}} / \mathrm{dt}\right)$ and $\max \left(\mathrm{f}_{\mathrm{D}}\right)$ exactly. The usable EUV and X-ray channels, however, do not cover the whole ionizing flux (In "Satellite data of EUV and X-ray
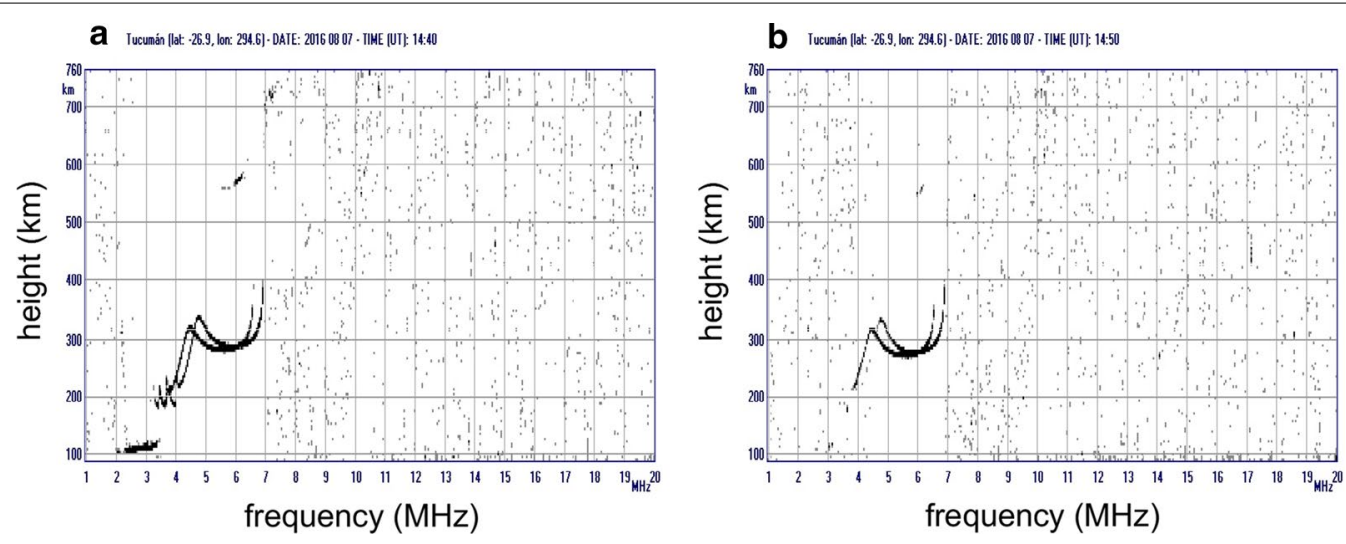

Fig. 12 lonograms recorded in Tucumán on 7 August 2016 at a 14:40 UT and b 14:50 UT 
fluxes" section). In addition, the relative role of different spectral ranges of the incoming flux on the ionization changes with height.

The role of the time derivative of EUV flux $\left(\mathrm{dF}_{\mathrm{EUV}} / \mathrm{dt}\right)$ is also obvious from the relations between the $\max \left(\mathrm{dF}_{\mathrm{EUV}} /\right.$ $\mathrm{dt}$ ) and the observed maxima of $\mathrm{u}_{\mathrm{p}}$ and electron density changes for various events presented in Table 2. In this table, each event is presented by the time of X-ray flux maximum and classification based on GOES measurements, estimated height of CDSS measurement at specific frequency (true heights from ionograms), maximum of absolute value of virtual velocity $u_{\mathrm{p}}^{*}$ maximum time change of electron density $-\max (\partial \mathrm{N} / \partial \mathrm{t})$, obtained from the maximum of Doppler shift by Eq. (5), maximum of the measured time derivative of EUV flux $\mathrm{dF}_{\mathrm{EUV}} / \mathrm{dt}$ in the GOES channel B-spectral range 25-35 nm (In "Satellite data of EUV and X-ray fluxes" section), solar elevation angle $\varepsilon$ at the time of $\max \left(\mathrm{dF}_{\mathrm{EUV}} / \mathrm{dt}\right)$, and a rough estimate of the effective $\max \left(\mathrm{dF}_{\mathrm{EUV}} / \mathrm{dt}\right)$, if the solar elevation angle is considered $\left(\sin (\varepsilon) \cdot \max \left(\mathrm{dF}_{\mathrm{EUV}} / \mathrm{dt}\right)\right)$. It should be noted in this respect that the uncertainty of $\partial \mathrm{N} / \partial \mathrm{t}$ might be several tens of percent because of the uncertainty of $\partial \mathrm{N} / \partial \mathrm{z}$ that is obtained from the measured true heights. Nevertheless, it is obvious that the value of $\max (\partial \mathrm{N} / \partial \mathrm{t})$ mainly depends on $\max \left(\mathrm{dF}_{\mathrm{EUV}} / \mathrm{dt}\right)$. For example, the $\max (\partial \mathrm{N} / \partial \mathrm{t})$ for the M7.9 event is about 4.1 larger than the $\max (\partial N / \partial t)$ for the stronger $\mathrm{X} 2.7$ event. On the other hand, the non-measurable $\mathrm{dF}_{\mathrm{EUV}} / \mathrm{dt}$ caused only small values of $u_{\mathrm{p}}^{*}$ and $\partial \mathrm{N} / \partial \mathrm{t}$ in the case of M1.3 and C8.5 events (Table 2); in addition, it is likely that acoustic gravity waves significantly contributed to the small values of $\mathrm{u}_{\mathrm{p}}^{\prime}$ and $\partial \mathrm{N} / \partial \mathrm{t}$ in these cases.

The attenuation of Doppler signal was investigated in the present study and compared with theoretical expectations. Most of the attenuation occurs in the lower ionosphere in the D and lower E region. The attenuation of Doppler signal was also compared with the attenuations measured by the nearby riometer in Tucumán. To the best of our knowledge, it was for the first time that attenuations measured by riometer and CDSS were compared. It should be noted that short-wave fadeouts of SuperDARN HF radar signals and their correlation with riometer measurements were recently discussed by Fiori et al. (2018). Systematic investigation and comparison of attenuations measured by different instruments operating at different frequencies during solar flares might potentially provide interesting information about the dynamics of electron densities at the heights of D and lower $\mathrm{E}$ layer. Differences in measurements at various frequencies may result from different electron density changes at different heights in the lower ionosphere and thus reduce the uncertainties in the D layer profile and its evolution during solar flares. As the riometer was installed in Tucumán in 2016 at the decreasing phase of the current solar cycle (SC24), it is expected that such a database will be obtained in the next solar cycle. In addition, construction of a riometer at the location of CDSS in the Czech Republic is underway. An update of CDSS is also considered to measure the received power in ordinary (L-O) and extraordinary (R-X) mode separately, which will enable a more exact calculation of the expected attenuation for the modeled profiles of electron densities and comparison with experiment.

The enhanced ionization in the D layer, regardless of the source of ionization, leads to decrease in the signalto-noise ratio and might cause echoes to not be detected at low frequencies. Therefore, ground-based studies of $\mathrm{E}$ and Es layer dynamics, e.g., from ionograms, should consider a possible attenuation of the sounding signal due to radio wave absorption in the $\mathrm{D}$ layer. Absorption in the $\mathrm{D}$ and lower $\mathrm{E}$ regions, using continuous signal of broadcasting stations, was often studied to identify ionospheric effects of solar flares (e.g., Laštovička 2009), or of planetary waves (e.g., Laštovička and Pancheva 1991), or winter anomaly in the lower ionosphere (e.g., Schwentek 1971). However, the broadcast transmitters changed

Table 2 Summary of presented events and observations

\begin{tabular}{|c|c|c|c|c|c|c|c|}
\hline $\begin{array}{l}\text { Date and time } \\
\text { of X-ray maximum } \\
\text { (UT) }\end{array}$ & $\begin{array}{l}\text { Event } \\
\text { classification }\end{array}$ & $\begin{array}{l}\text { Height of SFD } \\
\text { observation } \\
(\mathrm{km})\end{array}$ & $\max \left|u_{p}^{*}\right|(m / s)$ & $\max \partial \mathrm{N} / \partial \mathrm{t}\left(\mathrm{m}^{-3} / \mathrm{s}\right)$ & $\begin{array}{l}\max \mathrm{dF}_{\text {EUv }} / \\
\mathrm{dt}\left(\mathrm{W} / \mathrm{m}^{2} / \mathrm{s}\right)\end{array}$ & Solar elev $\varepsilon\left({ }^{\circ}\right)$ & $\begin{array}{l}\sin (\varepsilon) \cdot \max \\
\mathrm{dF}_{\mathrm{EUV}} / \mathrm{dt}(\mathrm{W} / \\
\left.\mathrm{m}^{2} / \mathrm{s}\right)\end{array}$ \\
\hline $22.10 .201414: 28$ & $X 1.6$ & $206(7.04 \mathrm{MHz})$ & 83 & $1.3 \times 10^{9}$ & $1.0 \times 10^{-6}$ & 15 & $0.26 \times 10^{-6}$ \\
\hline $22.10 .201414: 28$ & $x 1.6$ & $178(4.65 \mathrm{MHz})$ & 111 & $0.9 \times 10^{9}$ & $1.0 \times 10^{-6}$ & 15 & $0.26 \times 10^{-6}$ \\
\hline $22.10 .201414: 28$ & $\mathrm{x} 1.6$ & $154(3.59 \mathrm{MHz})$ & 142 & $0.5 \times 10^{9}$ & $1.0 \times 10^{-6}$ & 15 & $0.26 \times 10^{-6}$ \\
\hline 05.05.2015 22:11 & $\times 2.7^{*}$ & $185(6.57 \mathrm{MHz})$ & 34 & $0.7 \times 10^{9}$ & $1.6 \times 10^{-6}$ & 10 & $0.27 \times 10^{-6}$ \\
\hline 25.06.2015 08:16 & M7.9 & $250(6.57 \mathrm{MHz})$ & 179 & $2.9 \times 10^{9}$ & $15 \times 10^{-6}$ & 32 & $7.9 \times 10^{-6}$ \\
\hline 07.08.2016 14:44 & M1.3 & $200(4.63 \mathrm{MHz})$ & 10 & $0.05 \times 10^{9}$ & Low SNR & 40 & Low SNR \\
\hline 07.08.2016 15:09 & C 8.5 & $200(4.63 \mathrm{MHz})$ & 9 & $0.05 \times 10^{9}$ & Low SNR & 43 & Low SNR \\
\hline
\end{tabular}

* The observation of X2.7 by CDSS on 5 May 2015 was presented in the paper by Laštovička and Chum (2017) 
from constant strength of transmitted signal to variable strength to be more energy efficient in the late 1980s and early 1990s, which terminated this application. The strength of radio wave absorption can also be estimated from $f_{\text {min }}$, where $f_{\text {min }}$ is the lowest detected frequency in the ionogram, as has already been used in several studies (e.g., Fraser and Thorpe 1976; Stanford and Saksena 1989; Vergasova et al. 1995). However, $\mathrm{f}_{\text {min }}$ is not applicable for studying rapid processes such as SIDs due to the time resolution of standard ionosonde sounding.

\section{Conclusions}

Using high-time resolution data, on the order of seconds, it was experimentally shown that Doppler shift associated with solar flares depends on the time derivative of ionizing flux, especially in the EUV spectral range. The maximum Doppler shift was observed around the time when the rate of change of the ionizing flux was maximal, whereas it was negligible when the ionizing flux reached maximum. The measured increases of relative attenuation of Doppler signals corresponded well with the enhanced ionizing X-ray fluxes and were in rough agreement with calculations of expected attenuations based on modeled electron densities and electron-neutral collision frequencies. The relative attenuation measured by continuous Doppler sounding also correlated well with cosmic noise absorption obtained by riometer. A future systematic analysis of attenuations based on multi-instrument measurements operating at different frequencies could be used for investigation of dynamics at different heights of the lower ionosphere.

\section{Authors' contributions \\ $J C$ wrote most of the paper and performed most of the analysis, especially of the Doppler measurements. JU worked with GOES 15 data, JL helped with the text, MAC, FAMB and MF provided the ionosonde and riometer data in Tucumán and were also responsible for the operation of Doppler sounding in Tucumán, JYL provided the ionosonde data and was responsible for the operation of Doppler sounding in Taiwan, JF, and ZM helped with determin- ing of true heights from ionograms. All authors read and approved the final manuscript.}

\section{Author details \\ ${ }^{1}$ Institute of Atmospheric Physics CAS, Bocni II/1401, 14131 Prague 4, Czech Republic. ${ }^{2}$ Laboratorio de Telecomunicaciones, Facultad de Ciencias Exactas y Tecnología, Universidad Nacional de Tucumán, San Miguel de Tucumán, Argentina. ${ }^{3}$ Institute of Space Science, National Central University, Chung-Li 320, Taiwan. ${ }^{4}$ Consejo Nacional de Investigaciones Científicas y Técnicas (CONICET), Buenos Aires, Argentina.}

\section{Acknowledgements}

J. Baše and F. Hruška from the Institute of Atmospheric Physics CAS, Czech Republic, and Y. Chen from Taiwan are acknowledged for the development and maintenance of the Doppler system.

\section{Competing interests}

The authors declare that they have no competing interests.

\section{Availability of data and materials}

GOES-15 satellite data are available at NOAA National Centers for Environmental information http://www.ngdc.noaa.gov/. International Reference lonosphere model IRI-16 is available at http://www.irimodel.org/. The Doppler data in the form of spectrograms are available at http://datacenter.ufa.cas.cz/ under the link to Spectrogram archive.

\section{Consent for publication}

Not applicable.

\section{Ethics approval and consent to participate}

Not applicable.

\section{Funding}

The support under the grant 18-01969S by the Czech Science Foundation is acknowledged. The support under the Grant PICT 2015/0511 granted by FONCYT - ARG and MOST-18-05 by the Czech Academy of Sciences is also acknowledged.

\section{Publisher's Note}

Springer Nature remains neutral with regard to jurisdictional claims in published maps and institutional affiliations.

Received: 13 Auqust 2018 Accepted: 11 December 2018

Published online: 18 December 2018

\section{References}

Bilitza D, Altadill D, Zhang Y, Mertens C, Truhlik V, Richards P, McKinnell LA, Reinisch B (2014) The international reference ionosphere 2012 — a model of international collaboration. J Space Weather Space Clim 4:A07. https:// doi.org/10.1051/swsc/2014004

Chakraborty S, Ruohoniemi JM, Baker JBH, Nishitani N (2018) Characterization of short-wave fadeout seen in daytime SuperDARN ground scatter observations. Radio Sci 53:472-484. https://doi.org/10.1002/2017RS006488

Chum J, Bonomi FAM, Fišer J, Cabrera MA, Ezquer RG et al (2014) Propagation of gravity waves and spread $\mathrm{F}$ in the low-latitude ionosphere over Tucumán, Argentina, by continuous Doppler sounding: first results. J Geophys Res Space Phys 119:6954-6965. https://doi.org/10.1002/2014J A020184

Chum J, Liu JY, Laštovička J, Fišer J, Mošna Z, Baše J, Sun YY (2016) lonospheric signatures of the April 25, 2015 Nepal earthquake and the relative role of compression and advection for Doppler sounding of infrasound in the ionosphere. Earth Planets Space 68:24. https://doi.org/10.1186/s4062 3-016-0401-9

Chum J, Liu J-Y, Podolská K, Šindelárová T (2018) Infrasound in the ionosphere from earthquakes and typhoons. J Atmos Sol Terr Phys. https://doi. org/10.1016/j.jastp.2017.07.022

Davies K, Watts J, Zacharisen D (1962) A study of F2-layer effects as observed with a Doppler technique. J Geophys Res 67:2. https://doi.org/10.1029/ JZ067i002p00601

Fiori RAD, Koustov AV, Chakraborty S, Ruohoniemi JM, Danskin DW, Boteler DH Shepherd SG (2018) Examining the potential of the super dual auroral radar network for monitoring the space weather impact of solar X-ray flares. Space Weather. https://doi.org/10.1029/2018SW001905

Fraser GJ, Thorpe MR (1976) Experimental investigations of ionospheric/stratospheric coupling in southern mid latitudes-1. Spectra and cross-spectra of stratospheric temperatures and the ionospheric $f$-min parameter. J Atmos Terr Phys 38:1003-1011. https://doi.org/10.1016/00219169(76)90083-0

Fröhlich C (2009) Evidence of a long-term trend in total solar irradiance. Astron Astrophys 501:L27-L30. https://doi.org/10.1051/0004-6361/200912318

Gurnett DA, Bhatacharjee A (2005) Introduction to plasma physics with space and laboratory applications. Cambridge Univ. Press, New York

Haldoupis C (2012) Midlatitude Sporadic E. A typical paradigm of atmosphereionosphere coupling. Space Sci Rev 168:441. https://doi.org/10.1007/ s11214-011-9786-8 
Han F, Cummer SA (2010) Midlatitude daytime D region ionosphere variations measured from radio atmospherics. J Geophys Res 115:A10314. https:// doi.org/10.1029/2010JA015715

Jacobs JA, Watanabe T (1966) Doppler frequency changes in radio waves propagating through a moving ionosphere. Radio Sci 1(3):257-264

Kelley MC (2009) The Earth's ionosphere, plasma physics and electrodynamics, 2nd edn. Elsevier, Amsterdam

Kopp G (2016) Magnitudes and timescales of total solar irradiance variability. J Space Weather Space Clim 6:A30. https://doi.org/10.1051/swsc/2016025

Laštovička J (2009) Lower ionosphere response to external forcing: a brief review. Adv Space Res 43:1-14. https://doi.org/10.1016/j.asr.2008.10.001

Laštovička J, Chum J (2017) A review of results of the international ionospheric Doppler sounder network. Adv Space Res 1:1. https://doi.org/10.1016/j. asr.2017.01.032

Laštovička J, Pancheva D (1991) Changes in characteristics of planetary waves at 80-100 km over central and Southern Europe since 1980. Adv Space Res 11:(3)31-(3)34. https://doi.org/10.1016/0273-1177(91)90399-5

Liu JY, Berkey FT (1994) Phase relationships between total electron content variations, Doppler velocity oscillations and geomagnetic pulsations. J Geophys Res 99(A9):17539-17545. https://doi.org/10.1029/94JA00869

Liu JY, Chiu CS, Lin CH (1996) The solar flare radiation responsible for sudden frequency deviation and geomagnetic fluctuation. J Geophys Res 101(A5):10855-10862. https://doi.org/10.1029/95JA03676

Mathews JD (1998) Sporadic E: current views and recent progress. J Atmos Sol Terr Phys 60:413

McRae WM, Thomson NR (2004) Solar flare induced ionospheric D region enhancements from VLF phase and amplitude observations. J Atmos Terr Phys 66:77-87. https://doi.org/10.1016/j.jastp.2003.09.009

Mitra AP (1974) Ionospheric effects of solar flares. Astrophys Space Sci Libr. https://doi.org/10.1007/978-94-010-2231-6

Moro J, Denardini CM, Correia E, Abdu MA, Schuch NJ, Makita KA (2012) Comparison of two different techniques for deriving the quiet day curve from SARINET riometer data. Ann Geophys 30:1159-1168. https://doi. org/10.5194/angeo-30-1159-2012
Nishino M, Makita K, Yumoto K, Rodrigues FS, Schuch NJ, Abdu MA (2002) Unusual ionospheric absorption characterizing energetic electron precipitation into the South Atlantic magnetic anomaly. Earth Planets Space 54:907-916. https://doi.org/10.1186/BF03352438

Picone JM, Hedin AE, Drob DP (2001) NRLMSISE-00 empirical model of the atmosphere: statistical comparisons and scientific issues. J Geophys Res 107:1468. https://doi.org/10.1029/2002JA009430

Schwentek H (1971) Regular and irregular behaviour of winter anomaly in ionospheric absorption. J Atmos Terr Phys 33:1647-1650. https://doi. org/10.1016/0021-9169(71)90082-1

Shunk RW, Nagy AF (2009) lonospheres physics, plasma physics, and chemistry, 2nd edn. Cambridge University Press, Cambridge

Silber I, Price C (2016) On the use of VLF narrowband measurements to study the lower ionosphere and the mesosphere-lower thermosphere. Surv Geophys. https://doi.org/10.1007/s10712-016-9396-9

Smith EVP, Gottlieb DM (1974) Solar flux and its variations. Space Sci Rev 16(5-6):771-802

Stanford JL, Saksena RC (1989) Oscillations in D-region absorption at periods of one to two months. J Atmos Terr Phys 51:975-981. https://doi. org/10.1016/0021-9169(89)90012-3

Stix TH (1962) The theory of plasma waves. Mc Graw-Hill Book Comp, New York Sutcliffe PR, Poole AWV (1989) lonospheric Doppler and electron velocities in the presence of ULF waves. J Geophys Res 94(A10):13505-13514

Vergasova GV, Kazimirovsky ES, Kokourov VD, Petruchin VF (1995) Relationship between the radio wave absorption and horizontal winds in the lower ionosphere over East Siberia. J Geomagn Geoelectr 47:539-549

Veronig A, Brown J, Brian D, Schwartz R, Sui L, Kimberley T (2005) Physics of the Neupert effect: estimates of the effects of source energy, mass transport, and geometry using RHESSI and GOES data. Astrophys J 621:482-497. https://doi.org/10.1086/427274

Watanabe D, Nishitani N (2013) Study of ionospheric disturbances during solar flare events with the SuperDARN Hokkaido Radar. Adv Polar Sci 24:12-18. https://doi.org/10.3724/SP.J.1085.2013.00012

\section{Submit your manuscript to a SpringerOpen ${ }^{\circ}$ journal and benefit from:}

- Convenient online submission

- Rigorous peer review

- Open access: articles freely available online

- High visibility within the field

- Retaining the copyright to your article

Submit your next manuscript at $\boldsymbol{\nabla}$ springeropen.com 